Review

\title{
Evidence for a cytokine model of cognitive function
}

\author{
J. McAfoose, B.T. Baune* \\ Psychiatry and Psychiatric Neuroscience, School of Medicine and Dentistry, James Cook University, Townsville, Queensland 4811, Australia
}

\section{A R T I C L E I N F O}

\section{Article history:}

Received 1 July 2008

Received in revised form 10 October 2008

Accepted 11 October 2008

\section{Keywords:}

Cytokines

Cognition

CNS

TNF

IL-6

IL-1beta

IFN $\gamma$

Alpha(1)-antichymotrypsin

\begin{abstract}
A B S T R A C T
Aiming at a formulation of a cytokine model of cognitive function under immunologically unchallenged physiological conditions, this article reviews the cytokine biology in the central nervous system (CNS) and recent developments in normal cytokine functions within the CNS that subserve cognitive processes. Currently available evidence shows that the cytokines IL-1 $\beta$, IL- 6 and TNF- $\alpha$ play a role in complex cognitive processes at the molecular level, such as synaptic plasticity, neurogenesis, as well as neuromodulation. Such findings provide evidence for a cytokine model of cognitive function, which shows that cytokines play an intimate role in the molecular and cellular mechanisms subserving learning, memory and cognition under physiological conditions. These cytokine-mediated cognitive processes have implications in the long-term development and pathogenesis of specific neuropsychiatric disorders such as major depression and dementia. The identification of this central role of cytokines in various brain activities during health provides greater insight into normal brain functions, especially synaptic plasticity, memory and cognition, and facilitates the understanding of specific biological mechanisms involved in neuropsychiatric diseases, such as dementia and depression. In order to extend the suggested cytokine model of cognitive function onto other members of the cytokine family, future research is required to investigate the physiological effects of other cytokines such as interferon-gamma (IFN $\gamma$ ), alpha(1)-antichymotrypsin and IL-2 on cognitive function at the molecular level under immunologically unchallenged conditions.
\end{abstract}

(c) 2008 Elsevier Ltd. All rights reserved.

\section{Contents}

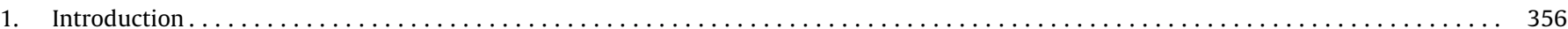

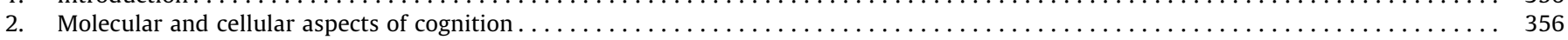

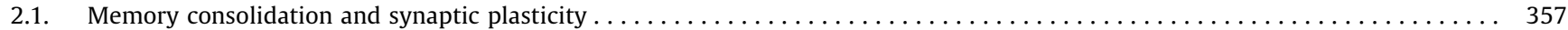

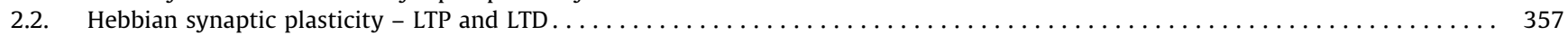

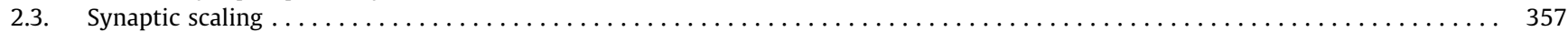

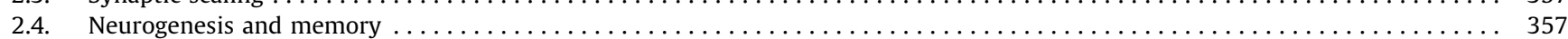

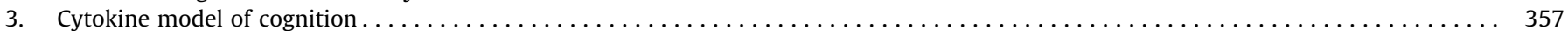

3.1. IL-1 influences cognitive function by affecting long-term potentiation and possibly neurogenesis. . . . . . . . . . . . . . 357

3.2. IL-6 impacts cognitive function via effects on neurogenesis and synaptic plasticity $\ldots \ldots \ldots \ldots . \ldots \ldots \ldots$

3.3. TNF alpha influences cognitive function through direct effects on LTP and synaptic scaling. . . . . . . . . . . . . . . . . . 360

3.4. Other potential mechanisms by which cytokines might mediate cognitive processes . . . . . . . . . . . . . . . . . 361

3.5. Other cytokines potentially influencing cognitive function $\ldots \ldots \ldots \ldots$

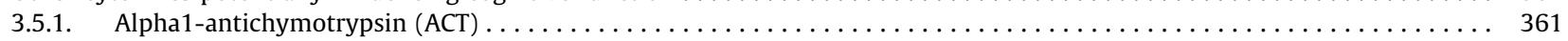

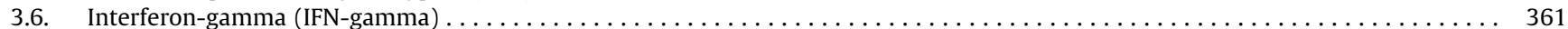

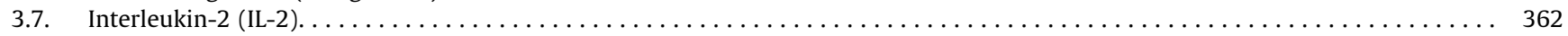

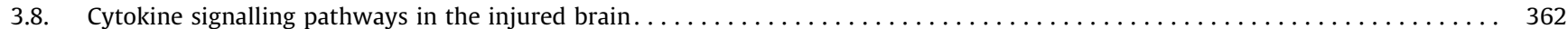

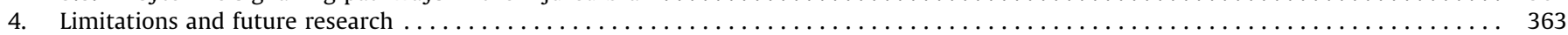

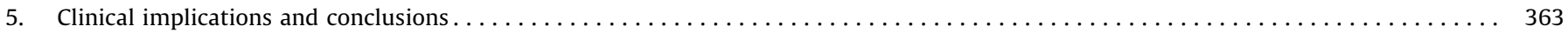

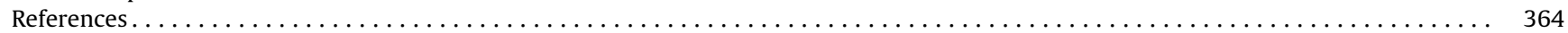

\footnotetext{
* Corresponding author. Tel.: +61 74781 6731; fax: +61 747816841 .

E-mail address: bernhard.baune@jcu.edu.au (B.T. Baune).
} 


\section{Introduction}

The interactions between the immune and central nervous systems (CNS) in pathological states such as multiple sclerosis and depression have long been under investigation. In recent years, the discovery of multiple functions of cytokines in the central nervous system suggests that cytokines play a central role in complex CNS functions such as cognition (Hopkins and Rothwell, 1995; Pollmacher et al., 2002; Rothwell, 1999; Rothwell and Hopkins, 1995; Wilson et al., 2002). Most notably, the over-expression of cytokines has been associated with numerous pathological states (both within the central and peripheral nervous system), such as infection (viral, bacterial and fungal), autoimmune disease (i.e. multiple sclerosis), stroke, trauma, neurodegenerative disease (i.e. Alzheimer's disease (AD) and other dementias) (Ransohoff and Benveniste, 2006; Rojo et al., 2008; Rothwell and Loddick, 2002; Shaftel et al., 2008; Viviani et al., 2004) and in neuropsychiatric disorders, such as depression (Anisman et al., 2008; Capuron and Dantzer, 2003; Dantzer et al., 2008; Irwin and Miller, 2007; Kronfol and Remick, 2000; Raison et al., 2006). More specifically, some cytokines, such as interleukin 1 beta (IL-1-beta), interleukin 6 (IL-6) and tumor necrosis factor (TNF) have been associated with cognitive decline and dementia in several cross-sectional and prospective population studies (Dik et al., 2005; Holmes et al., 2003; Schmidt et al., 2002; Wilson et al., 2002). In addition, cytokines, such as TNF and IL-1-beta have been related to Alzheimer's disease in clinical cohorts (Dik et al., 2005; Holmes et al., 2003).

It is now believed that cytokine-mediated pathophysiological processes underlie the cognitive impairments associated with several neuropsychiatric diseases, making cytokines ideal targets for therapeutic intervention (Reichenberg et al., 2001; Tobinick, 2007; Tweedie et al., 2007; Wilson et al., 2002). Despite these pathological implications (Bitsch et al., 2000; He et al., 2007), cytokines have also been shown to exert physiological (Blatteis, 1990; Sei et al., 1995; Vitkovic et al., 2000a) and even neuroprotective (Pan and Kastin, 2001; Schwartz et al., 1991, 1994) functions.

Research by this group suggests that in healthy elderly humans cytokines, in particular interleukin 8 , under physiological conditions, are possibly involved in cognitive processes such as memory, perceptual speed and motor function (Baune et al., 2008a). Moreover, this group recently reported the associations between genetic variants of cytokines (IL-1 beta, IL- 6 and TNF) and cognitive function in healthy elderly humans in the general population (Baune et al., 2008b). More specifically, the results suggest that genetic variants of TNF may have protective effects in cognitive function such as perceptual speed (Baune et al., 2008b). In an animal model of cytokine-mediated cognitive function such as memory and learning, we were able to demonstrate that the presence of TNF under immunologically non-challenged conditions is essential for normal functions of memory and learning (Baune et al., 2008). This research linking complex cognitive phenotypes and cytokine effects in the CNS is well based on previous evidence to suggest that cytokines play a role in normal CNS function at a cellular and molecular level (see Jankowsky and Patterson, 1999 for review). For instance, during health both IL-1 and TNF have been shown to act as neuromodulators, as well as, pro-inflammatory factors (Blatteis, 1990; Sei et al., 1995; Vitkovic et al., 2000a,b).

Although these detrimental effects on cognitive function in both over-expressing and cytokine deficient models suggest that cytokines play an important physiological role in the CNS at the molecular and cognitive level, it still remains to be fully understood as to how cytokines participate in the molecular and cellular mechanisms subserving complex CNS functions such as learning, memory and cognition. Interestingly, growing evidence suggests that in particular the cytokines IL-1, IL-6 and TNF are involved in the molecular and cellular mechanisms subserving complex cognitive processes (Pickering and O'Connor, 2007; Vitkovic et al., 2000b; Viviani et al., 2007). While direct and indirect evidences show that IL-1, IL-6 and TNF may play a major role in synaptic plasticity, long-term potentiation (LTP), neurogenesis and memory consolidation, the evidence for involvement with cognitive function is less conclusive for other cytokines such as interferon-gamma (IFN $\gamma$ ) (Baron et al., 2008), alpha(1)-antichymotrypsin (ACT) (Dik et al., 2005; McIlroy et al., 2000; Nilsson et al., 2004) and IL-2 (Beck et al., 2002, 2005a,b).

In this review, we propose a cytokine model of cognitive function during health under immunologically unchallenged conditions. Aiming to establish an improved understanding of cytokine-mediated cognitive function during physiological conditions, current scientific literature on cytokine biology and their related activities within the CNS during healthy immunologically unchallenged conditions was reviewed. In particular, this review primarily concentrates on the cytokines IL-1, IL- 6 and TNF- $\alpha$ as these cytokines have been shown to be involved in the molecular mechanisms underlying learning and memory consolidation. In addition, we also review other cytokines, especially IFN $\gamma$, ACT and IL-2 which have significant implications in neurogenesis and possibly in complex cognitive processes such as learning and memory consolidation, although their potential molecular mechanisms in learning and memory are not sufficiently studied at this stage.

This approach allows the distinction between cytokines providing conclusive evidence for a cytokine model of cognitive function and those cytokines suggestive of their involvement in higher cognitive function under physiological healthy conditions. It is intended that the models of physiological cytokine activities and properties as described in this review propose a cytokinemediated model of cognitive function that would provide further understanding into pathological consequences of cytokines during disease. Finally, this review discusses current limitations, clinical implications and future research of a cytokine model of cognitive function.

\section{Molecular and cellular aspects of cognition}

Cognition often refers to a collection of cognitive processes, such as attention, executive function, learning and memory, consciousness, and language. Of these cognitive processes, there has been particular interest in recent years on the involvement of cytokines in learning and memory processes. More specifically, this area of research has largely directed its efforts at clarifying the role that cytokines play in hippocampal-dependent learning and memory; i.e., spatial memory, object recognition and contextual fear conditioning. The reasons for a focus on learning and memory processes in this review are that, firstly the neuronal mechanisms underlying higher cognitive functions such attention, executive function, consciousness and language and their relationship with cytokines remain poorly understood and secondly these other higher cognitive processes appear to rely heavily on learning and memory processes. Moreover, since the hippocampal formation appears to play a major role in memory consolidation, an emphasis was placed, in this review, on how cytokines participate in the well known and extensively studied molecular and cellular processes thought to be subserving memory formation.

As a consequence, in this review we firstly focus on the involvement of cytokines in these molecular and cellular processes and secondly we emphasize on the involvement of cytokines in 
learning and memory processes as the basis for the proposed cytokine model of cognitive function. A brief overview will be given on the molecular processes of memory consolidation and synaptic plasticity before evaluating and discussing the involvement of a number of cytokines in these molecular processes.

\subsection{Memory consolidation and synaptic plasticity}

In brief, 'memory consolidation' is the neuropsychological mechanism and/or structural changes within the brain that allows memories to be stored more permanently. Supported by neuroimaging results (i.e. Bosshardt et al., 2005; Lepage et al., 1998) it is now widely believed that activation of the hippocampal formation is associated with memory consolidation; at least for some forms of memory. In concurrence with these findings, some (Buckner, 2003; Knowlton and Fanselow, 1998; Meeter and Murre, 2005; Nadel and Moscovitch, 1997) have suggested that memory consolidation is collectively contingent on hippocampal/entrorhinal and cortical interactions.

Although the exact neurobiological mechanisms subserving memory consolidation remain to be fully understood, three proposed cellular/molecular mechanisms have received wide acceptance; Hebbian plasticity (Malenka and Bear, 2004), synaptic scaling (Burrone and Murthy, 2003; Perez-Otano and Ehlers, 2005; Turrigiano, 2007), and adult neurogenesis (Bruel-Jungerman et al., 2007a,b; Drapeau et al., 2007). Although it was widely believed that these mechanisms were independent of each other, there is now evidence showing that these different forms of synaptic plasticity are functionally linked and act as associate partners during the formation and retention of memories (see BruelJungerman et al., 2007a for further details).

\subsection{Hebbian synaptic plasticity - LTP and LTD}

One of the earliest and most widely accepted neurobiological theories as to how memories are consolidated is Hebbian synaptic plasticity. According to this theory a synapse will be strengthened if the pre-synaptic neuron is active while the post-synaptic neuron is firing; a process called Hebbian modification (Hebb, 1949). During repeated synaptic excitations of a single synapse (sensitization) or multiple synapses simultaneously (conditioning), neurons become 'potentiated' or highly responsive, for minutes, days, or weeks. This has lead to the suggestion that long-term potentiation and long-term depression (LTD), which is, respectively, the strengthening or weakening of synaptic connectivity due to stimulation, is the underlying cellular/molecular mechanism subserving memory consolidation (Lynch, 2000; Lynch et al., 2007; Lynch, 2004; Ziemann et al., 2004). In support of this notion, research has shown that (1) the presence of LTP and LTD is widely distributed throughout the mammalian brain, especially within the hippocampus, (2) learning modifies subsequent induction of both LTP and LTD and (4) inhibition of LTP and LTD impairs memory (Lynch et al., 2007; Lynch, 2004; Malenka and Bear, 2004; Ziemann et al., 2004).

\subsection{Synaptic scaling}

Despite wide acceptance for Hebbian synaptic plasticity, this form of plasticity operates via positive feedback mechanisms that, if left unchecked, tend to destabilize neuronal networks over time (Perez-Otano and Ehlers, 2005; Turrigiano, 1999, 2007). In order to maintain synaptic strength and plasticity, Hebbian plasticity requires the regulation of synapse-specific LTP and LTD at both the cell-wide and network level (Abbott and Nelson, 2000). A nonHebbian form of synaptic plasticity, called homeostatic synaptic scaling, appears to serve this function. During prolonged periods of inactivity or hyperactivity, homeostatic synaptic scaling stabilizes the activity of neurons and networks (Abbott and Nelson, 2000; Burrone and Murthy, 2003; Echegoyen et al., 2007; Perez-Otano and Ehlers, 2005; Turrigiano, 2007), thus facilitating Hebbian synaptic plasticity, and possibly memory consolidation (Renart et al., 2003).

\subsection{Neurogenesis and memory}

There is also considerable evidence to suggest that adult neurogenesis plays an important role in memory consolidation, and hippocampal-dependent learning (Bruel-Jungerman et al., 2006, 2007a,b; Drapeau et al., 2007; Saxe et al., 2006; Snyder et al., 2001). For instance, research by Dupret et al. (2007), suggests that spatial learning involves learning-induced regulation of new hippocampal neurons, in which both the removal (i.e. apoptosis) and addition (neurogenesis) of hippocampal neurons contribute to memory formation. However, research by Shors et al. (2002) and Saxe et al. (2007), suggests that neurogenesis may be associated with some forms of hippocampal-dependent memory but not others. The exact mechanisms by which neurogenesis facilitates memory formation remains to be fully understood. Moreover, future research is also needed to clarify the relationship between neurogenesis and both Hebbian and non-Hebbian forms of synaptic plasticity.

\section{Cytokine model of cognition}

Interestingly, both the over-expression and absence of cytokines have been shown to directly influence hippocampaldependent forms of memory and various forms of synaptic plasticity. Although the exact mechanisms as to how cytokines participate in the molecular and cellular processes thought to be subserving memory formation remains to be fully understood, significant advances have been made in elucidating these cytokine-mediated molecular and cellular processes. This section will therefore concentrate on what is known about cytokinemediated neuronal plasticity and how these processes might influence memory and cognition. In particular, this section will focus on IL-1 $\beta$, TNF $\alpha$ and IL-6, which have been the subject of extensive scientific investigation in this context. In addition, the potential involvement of other cytokines such as IFN $\gamma$, ACT and IL2 are evaluated and discussed in this context. Other possible mechanisms as to how cytokines might influence cognitive processes will also be given based on the known biological properties of cytokines. Moreover, for the sake of clarity, a brief introduction will be given on each cytokine and their associated receptors.

\subsection{IL-1 influences cognitive function by affecting long-term potentiation and possibly neurogenesis}

The IL-1 family of cytokines is a growing cytokine family, which hitherto consists of the following cytokines, IL-1 $\alpha$ (IL-1F1), IL-1 $\beta$ (IL-1F2), IL-1 receptor antagonist (IL-1ra or IL-1F3), IL-18 (IL-1F4) and IL-1F5-10. IL- $1 \alpha$ and IL-1 $\beta$ display high sequence homology, and both exist as inactive forms (pro-IL- $1 \alpha$ and pro-IL-1 $\beta$ ) until they are cleaved by calpain and caspase-1, respectively. Once cleaved, biologically activate IL- $1 \alpha$ remains intracellular, whereas, IL-1 $\beta$ is secreted by a non-classical pathway. To date, two membrane-bound IL-1 receptors, type 1 (IL-1 R1) and type 2 (IL-1 R2), have been shown to bind IL-1 $\alpha$, IL-1 $\beta$ and IL-1ra. Although, IL- $1 \alpha$ and IL- $1 \beta$ bind to both receptors, evidence suggests that IL-1 R1 mediates all of the responses of IL-1, whereas, 
IL-1 R2 appears to have no signalling properties (Colotta et al., 1993, 1994). It has also been shown that IL-1 R1 has a higher binding affinity for IL- 1 ra then both IL- $1 \alpha$ and IL- $1 \beta$, whereas, IL-1 R2 displays a higher binding affinity for IL-1 $\beta$ than IL- $1 \alpha$. Such binding and receptor properties allow IL-1ra to act strongly as an IL-1 antagonist. Moreover, since IL-1 R2 lacks signalling properties and has a high binding affinity for IL-1 $\beta$, IL-1 R2 is believed to regulate IL- 1 activity, especially IL-1 $\beta$, by functioning as a decoy receptor (Colotta et al., 1993, 1994; Re et al., 1996). Both IL-1 R1 and IL-1 R2 can exist as soluble receptors after shedding. Although both soluble forms were originally believed to act antagonistically by sequestering biologically active and pro-IL-1, it is now believed that soluble IL-1 R1 (sIL-1 R1) can initiate signal transduction by binding to IL-1R accessory protein (Allan et al., 2005). Although the exact role in which these signalling and antagonistic mechanisms might play in central nervous system function remains to be fully understood, one possibility is neuromodulation or synaptic plasticity.

Previous research has suggested that IL-1 $\beta$ can modulate synaptic transmission in the hippocampus and appears to inhibit LTP induction (Bellinger et al., 1993; Cunningham et al., 1996; Katsuki et al., 1990; Murray and Lynch, 1998). Failing to confirm such findings, Schneider et al. (1998) demonstrated that increased local production of IL-1 $\beta$ in the hippocampus plays a role in LTP maintenance. As noted by Schneider et al. (1998), this alternative finding might have occurred because of the high concentration levels used in previous studies, which were more comparable to levels seen during pathological and inflammatory states then normal physiological conditions. Subsequent work (i.e. Coogan et al., 1999; Ross et al., 2003) has confirmed that at least under physiological conditions IL-1 $\beta$ is required for LTP maintenance, whereas, higher concentration of IL-1 $\beta$, under pathophysiological conditions, inhibits LTP. Together these findings suggest that IL-1 plays an intimate role in synaptic plasticity and that through these mechanisms possibly an important role in memory consolidation (see Fig. 1).

Cognitive-behavioural studies in animals (see Table 1 for details) have repeatedly shown that IL-1 $\beta$ influences various types of hippocampal-dependent memory (Brennan et al., 2003; Yirmiya et al., 2002). Moreover, research by Depino et al. (2004), has recently demonstrated that endogenous IL- $1 \alpha$ also participates in hippocampal memory processing. As reviewed by Pugh et al. (2001), there is considerable evidence to suggest that IL-1 might under physiological conditions play a role in memory consolidation processes. However, during stress, aging and disease, IL-1 appears to elicit memory impairment (Pugh et al., 2001). In support of these findings, IL-1 $\beta$ has recently been demonstrated to play a dual role in hippocampal-dependent memory processes (Avital et al., 2003; Goshen et al., 2007b). More specifically, it was demonstrated by these authors that the involvement of IL-1 $\beta$ in hippocampal-dependent memory follows an inverted U-shape pattern, in that basal levels of IL-1 $\beta$ are required for normal memory function, and any deviation from this physiological range (either deletion or elevation) results in impaired memory (Avital et al., 2003; Goshen et al., 2007b). Research by Avital et al. (2003), further demonstrated that impaired memory in IL- 1 receptor type 1 knockout mice, coincided with deficits in synaptic plasticity. Moreover, as recently shown by Young et al. (2007, \#234), increased levels of IL-1 disrupts an LTP-associated spinal learning paradigm (Grau et al., 2006), suggesting that IL-1 over-expression might impair LTP-associated learning processes possibly throughout the neuroaxis (Deak, 2007). Although not fully understood, these findings provide strong evidence to support a direct link between synaptic plasticity, IL-1 and cognitive functioning.
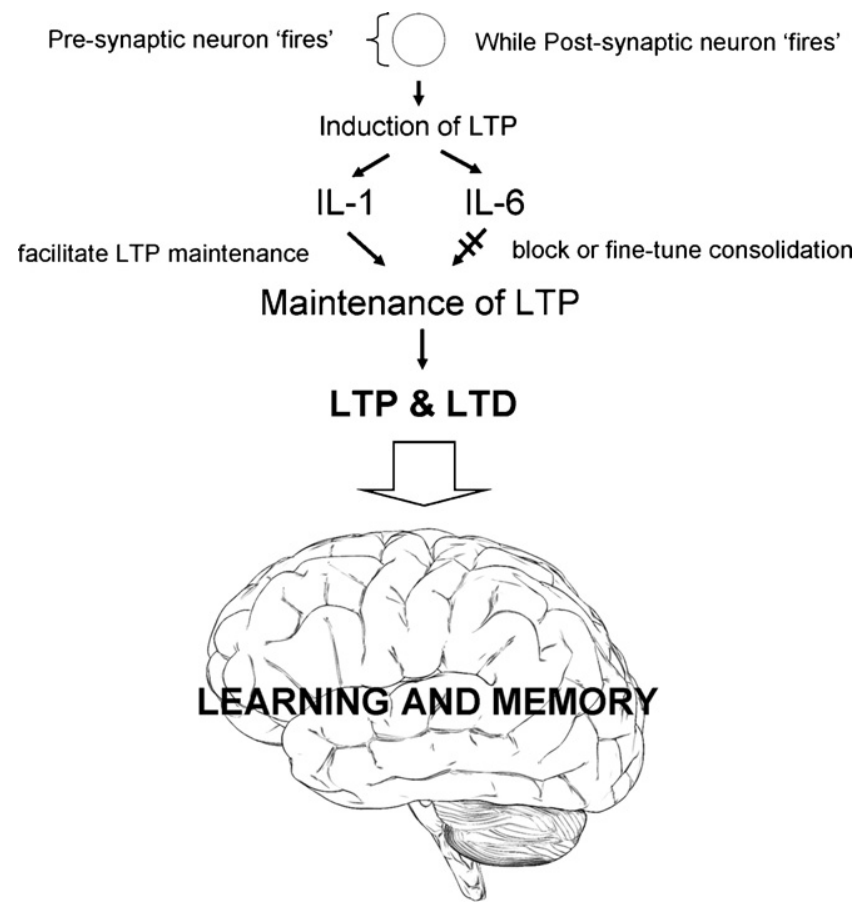

Fig. 1. Schematic illustration of the involvement of IL-1 and IL-6 in Hebbian synaptic plasticity, such as LTP and LTD. Essentially this process can be divided into three stages. In stage 1 , the simultaneous neuronal activity (firing) of both pre-synaptic and post-synaptic neurons results in the induction of LTP. This induction of LTP leads to the production of both IL-1 and IL-6 (stage 2). Finally in stage 3, LTP maintenance is fine-tuned by the overall level of expression of both IL-1 (facilitates) and IL-6 (blocks), thus influencing the consolidation of learning and memory.

Finally, recent investigations which explored the involvement of IL-1 in neurogenic processes during disease, stress and inflammatory states (Ben Menachem-Zidon et al., 2007; Goshen et al., 2007a; Kaneko et al., 2006; Koo and Duman, 2008; Spulber et al., 2008), have demonstrated that IL-1 can mediate neurogenesis. Although these processes have not been investigated during physiological conditions, there is reason to suggest that this relationship between IL-1 and neurogenesis might, in turn, have an impact on hippocampal-dependent learning and cognitive processes during health (Bruel-Jungerman et al., 2005; Drapeau et al., 2003; Saxe et al., 2007; Shors et al., 2002). Future research should therefore address the relationship between physiological levels of IL-1 and neurogenesis, and how these processes might influence cognitive function.

\subsection{IL-6 impacts cognitive function via effects on neurogenesis and synaptic plasticity}

Despite evidence to suggest that IL-6 plays an important role in neurodegenerative disease (Harding et al., 2005; Marsland et al., 2006; Rosenberg, 2005; Schram et al., 2007; Weaver et al., 2002; Wright et al., 2006), little is known about the biological actions of IL-6 during health and how these processes influence cognition. This section will therefore concentrate on what is known about the physiological functions of IL-6 within the brain during health; although data on how IL-6 over-expression might affect cognitive function will be briefly discussed. As an introduction to these biological functions of IL- 6 in the brain, we briefly outline the synthesis, receptor signalling and signal-transduction pathways of this cytokine.

In the CNS IL-6 is principally synthesized by astrocytes, and to a lesser extent, microglial, and neurons. As with other cytokines IL-6 
Table 1

Cognitive-behavioural studies investigating the involvement of cytokines in learning and memory processes.

\begin{tabular}{|c|c|c|c|c|c|}
\hline Study & Species & Animal model & Cytokine & Cognitive-behavioural test & Findings \\
\hline Yirmiya et al. (2002) & Rat & $\begin{array}{l}\text { Long Evans hooded rats (i.c.v. IL-1 } \beta \text {, } \\
\text { IL-1ra or saline injections) }\end{array}$ & IL-1 & $\begin{array}{l}\text { Passive avoidance and } \\
\text { Morris water maze }\end{array}$ & $\begin{array}{l}\text { IL-1 plays a critical role in hippocampal- } \\
\text { dependent learning and memory processes }\end{array}$ \\
\hline Brennan et al. (2003) & Rat & $\begin{array}{l}\text { Sprague-Dawley rats (i.p. IL- } 1 \beta \\
\text { injections }-1,3,6 \mu \mathrm{g} / \mathrm{kg} \text { or saline) }\end{array}$ & IL-1 & Leverpress avoidance task & $\begin{array}{l}\text { Low or moderate doses of IL- } 1 \text { improved } \\
\text { performance on leverpress avoidance task }\end{array}$ \\
\hline Depino et al. (2004) & Rat & Wistar rats & IL-1 & Inhibitory avoidance task & $\begin{array}{l}\text { Endogenous hippocampal IL-1 modulates a } \\
\text { fear-motivated learning task; suggesting IL-1 } \\
\text { to be apart of hippocampal memory processing }\end{array}$ \\
\hline Pugh et al. (2001) & Rat & $\begin{array}{l}\text { Rats - induced IL- } 1 \text { activity } \\
\text { (i.c.v. IL-1 } \beta, \text { gp } 120 \text { and i.p. LPS } \\
\text { injections and social isolation) }\end{array}$ & IL-1 & $\begin{array}{l}\text { Auditory and contextual } \\
\text { fear conditioning }\end{array}$ & $\begin{array}{l}\text { Increased IL-1 levels adversely affect } \\
\text { hippocampal-dependent memory } \\
\text { consolidation processes }\end{array}$ \\
\hline Avital et al., 2003 & Mouse & $\begin{array}{l}\text { wt and IL-1rKO mice } 129 / \\
\text { Sv } \times \text { C57BL/ } 6 \text { background }\end{array}$ & IL-1 & $\begin{array}{l}\text { Morris water maze and } \\
\text { contextual fear } \\
\text { conditioning }\end{array}$ & $\begin{array}{l}\text { IL-1 participates in hippocampal-dependent } \\
\text { memory processes synaptic plasticity }\end{array}$ \\
\hline Goshen et al. (2007a,b) & Mouse & $\begin{array}{l}\text { wt and IL- } 1 \text { raTG mice }(\mathrm{C} 57 \mathrm{BL} / \\
6 \times \mathrm{CBA}) \text { and } w \mathrm{t} \text { and IL- } 1 \text { rKO mice } \\
(129 / \mathrm{Sv} \times \mathrm{C} 57 \mathrm{BL} / 6)\end{array}$ & IL-1 & $\begin{array}{l}\text { Morris water maze and } \\
\text { contextual fear } \\
\text { conditioning }\end{array}$ & $\begin{array}{l}\text { IL-1 exerts a dual role in hippocampal- } \\
\text { dependent memory processes; an inverted } \\
\text { U-shaped pattern - i.e. the absence and } \\
\text { over-expression of IL- } 1 \text { impairs memory }\end{array}$ \\
\hline Braida et al. (2004) & Mouse & $\begin{array}{l}\text { wt and IL- } 6-1-\text { mice CBA } \\
\times \text { C57BL/6 background }\end{array}$ & IL-6 & $\begin{array}{l}\text { Passive avoidance and } \\
\text { radial maze }\end{array}$ & $\begin{array}{l}\text { Transgenic IL- } 1 \text { knockout mice demonstrated } \\
\text { improved radial maze and passive avoidance } \\
\text { learning }\end{array}$ \\
\hline Hryniewicz et al. (2007) & Mouse & $\begin{array}{l}\text { wt and IL-6-I- mice C57BL/6 } \\
\text { background }\end{array}$ & IL-6 & $\begin{array}{l}\text { Novel object recognition } \\
\text { task }\end{array}$ & $\begin{array}{l}\text { IL- } 6 \text { knockout mice displayed impaired } \\
\text { recognition memory, suggesting that } \\
\text { endogenous IL-6 plays a role in recognition } \\
\text { memory }\end{array}$ \\
\hline Baune et al. (2008) & Mouse & $\begin{array}{l}\text { wt, TNF- }- \text {-, TNF R1 and R2 } \\
\text { knockout C57BL/6 background }\end{array}$ & TNF & $\begin{array}{l}\text { Barnes maze and novel } \\
\text { object recognition task }\end{array}$ & $\begin{array}{l}\text { Absence of TNF has detrimental effects on } \\
\text { cognition performance, that is not receptor } \\
\text { specific }\end{array}$ \\
\hline Fiore et al. (1996) & Mouse & $\begin{array}{l}\text { wt and Tg6074 }(\mathrm{TNF} \text { over- } \\
\text { expression) } \mathrm{CBA} \times \mathrm{C} 57 \mathrm{Bl} / 6 \\
\text { background }\end{array}$ & TNF & Passive avoidance & $\begin{array}{l}\text { Transgenic mice demonstrated altered learning } \\
\text { and memory process; a retardation in passive } \\
\text { avoidance acquisition }\end{array}$ \\
\hline Fiore et al. (2000) & Mouse & $\begin{array}{l}\text { wt, Tg6074 and TgK3 }(\mathrm{TNF} \\
\text { over-expression) } \mathrm{CBA} \times \mathrm{C} 57 \mathrm{BL} / 6 \\
\text { background }\end{array}$ & TNF & $\begin{array}{l}\text { Passive avoidance and } \\
\text { Morris water maze }\end{array}$ & $\begin{array}{l}\text { TNF over-expression in the brain results in } \\
\text { disrupted learning capabilities and altered NGF } \\
\text { and NPY expression levels }\end{array}$ \\
\hline Aloe et al. (1999) & Mouse & $\begin{array}{l}\text { wt, Tg6074 and TgK3 }(\mathrm{TNF} \\
\text { over-expression) } \mathrm{CBA} \times \mathrm{C} 57 \mathrm{BL} / 6 \\
\text { background }\end{array}$ & TNF & Morris water maze & $\begin{array}{l}\text { Transgenic mice demonstrated memory } \\
\text { impairments and altered NGF and BDNF } \\
\text { expression levels }\end{array}$ \\
\hline
\end{tabular}

exerts multiple physiological functions within the CNS, which are both neuroprotective and neurodegenerative. IL- 6 exerts these biological effects through the formation of a hexameric receptor ligand complex (i.e. the binding of IL-6 to IL-6 receptor, which then leads to the homodimerization of gp130, the co-receptor of the IL-6 receptor), which subsequently induces signalling (Ward et al., 1994). The IL-6 receptor, through alternative splicing and shedding, also exists as a soluble form (sIL-6R), which unlike most other soluble cytokine receptors, functions as an agonist. IL-6 mediated responses are, therefore, greatly enhanced by the presence of sIL-6R (Van Wagoner et al., 1999; Van Wagoner and Benveniste, 1999). Moreover, sIL-6R can activate signalling responses in non-IL-6 cells (i.e. cells lacking IL-6 receptors) which express gp130; i.e. through the binding of sIL-6R with gp130. Distinct regions of gp130 activate specific signal-transduction pathways, such as the JAK-STAT, Ras-MAPK and PI-3 kinase (Hirano et al., 1997). Such findings might help explain the redundancy and antagonistic effects seen by cytokine receptors, especially the IL-6 family; although this remains to be clarified.

Recent studies suggest that neurogenesis is important for cognitive function and modulating memory function, such as, memory consolidation and some types of hippocampal-dependent learning (Bruel-Jungerman et al., 2005; Drapeau et al., 2003; Saxe et al., 2007; Shors et al., 2002). Research by Dupret et al. (2007) has, for instance, shown that learning-induced regulation of adult neurogenesis plays an important role in spatial learning, and that dysregulation of hippocampal neurogenesis may underlie age related memory deficits (Drapeau et al., 2003, 2007). Interestingly, IL- 6 has been shown to be an important regulator of neurogenesis.
As shown by Vallieres et al. (2002), adult transgenic mice which over-express IL- 6 by astroglia demonstrated a $63 \%$ reduction in neurogenesis in the hippocampal dentate gyrus. Furthermore, research by Monje et al. (2003) has also linked increased IL-6 levels with neural stem cell dysfunction and an associated decline in learning and memory. Such findings demonstrate that the longterm exposure to IL-6, as seen in normal aging (Godbout and Johnson, 2004) and certain neurodegenerative diseases can interfere with cognitive functioning by impairing adult neurogenesis. However, what remains to be clarified is whether basal levels of IL-6 during health participate in cognitive processes.

As investigated by Braida et al. (2004), transgenic mice not expressing IL-6 demonstrated improved cognitive functioning, as indicated by improved radial maze learning and a reduced amnesic effect of scopolamine during passive avoidance testing compared to wild-type mice (see Table 1 ). In particular, both young and old IL-6 transgenic mice, in comparison to wild-type mice, demonstrated superior and faster acquisition, in terms of both reduced number of working memory errors and shorter time and higher percentage to reach the criterion. On the other hand, research by Hryniewicz et al. (2007), has shown that IL-6 deficiency disrupts object recognition memory, as indicated by less time spent exploring the novel object, which suggests that transgenic IL-6 mice fail to distinguish novel objects from familiar objects (see Table 1). One possible explanation for this discrepancy is that basal levels of IL-6 influence neurogenesis, which in turn mediates some types of hippocampal-dependent forms of learning and memory but not others; although other mechanisms involving choline acetyltransferase (Itzhak and Achat-Mendes, 2004), $\mu$-opioid 
receptors, neurodevelopmental anomalies and synaptic plasticity cannot be ruled out (see Braida et al., 2004; Gurwitz, 1997). Despite apparently opposite results, these two experiments do however demonstrate that endogenous IL-6 plays an important role in cognitive function during physiological conditions.

As repeatedly shown, IL-6 also appears to influence synaptic plasticity (Balschun et al., 2004; Jankowsky et al., 2000; Li et al., 1997; Tancredi et al., 2000). As indicated by Li et al. (1997), exogenous IL-6 can suppress the induction of LTP without disrupting previously established LTP. This inhibitory effect of IL-6 on synaptic plasticity has been subsequently shown by Tancredi et al. (2000), to be mediated through mitogen-activated protein kinase ERK (MAPK/ERK). The demonstration that IL-6 is upregulated following LTP induction (Jankowsky et al., 2000) has provided further evidence that IL- 6 may be involved in synaptic plasticity. In support of such findings, Balschun et al. (2004), have shown that neutralizing IL-6 after tetanisation strengthens LTP maintenance. According to the authors, IL-6 appears to play a role in synaptic plasticity opposite to IL-1 and LTP maintenance (Balschun et al., 2004) (see Fig. 1). It has, therefore, been hypothesized that IL-6 under basal conditions may regulate or fine-tune the consolidation of long-term synaptic plasticity and hippocampal-dependent learning by opposing, in a negativefeedback fashion, the effects of IL-1 on LTP maintenance (Balschun et al., 2004) and/or by curtailing synaptic enhancement at neighbouring synapses (Jankowsky et al., 2000). Further research is needed to elucidate the role in which IL-6 plays in synaptic plasticity, neurogenesis and cognitive function, during health and pathological conditions in which increased levels of IL- 6 have been implicated.

\subsection{TNF alpha influences cognitive function through direct effects on LTP and synaptic scaling}

Tumor necrosis factor is a pro-inflammatory cytokine which has been shown to exert physiological, neuroprotective (Cheng et al., 1994; Gemma et al., 2007; Pan and Kastin, 2001; Schwartz et al., 1994) and neurodegenerative (Perry et al., 2001) effects within the nervous system. These pleiotropic effects are exerted by TNF via activation of two receptors, TNF-p55 receptor and TNF-p75 receptor. Often referred to as TNF-R1 and TNF-R2 respectively, these two distinct receptors have been shown to elicit different molecular and cellular responses (Baud and Karin, 2001; Chen and Goeddel, 2002; MacEwan, 2002a,b; Wajant et al., 2003). For instance, TNF-R1 has been shown to initiate the activation of caspases and ultimately apoptosis (MacEwan, 2002a,b). This 'death-signalling' intracellular pathway appears to be activated by a specific cytoplasmic domain identified in TNF-R1, referred to as the 'death domain'. TNF-R2 lacks this 'death domain' and appears to inhibit the activation of caspases and protect against apoptosis; albeit there is some evidence to suggest that TNF-R2 activation can induce cell death (see Wajant et al., 2003 for further details).

Recent research shows considerable advancement in the understanding of TNF bioactivity within the CNS. For example, TNF has the biological property to act as a neuromodulator within the brain (Blatteis, 1990; Szelenyi, 2001; Vitkovic et al., 2000a,b). Moreover, TNF has been shown to play a role in both glutamate excitotoxicity (i.e. by inhibiting glutamate transporters on astrocytes) and glutamate transmission (see Pickering et al., 2005 for a review). More specifically, Beattie et al. (2002) demonstrated that glial-derived TNF markedly influenced synaptic efficacy by upregulating surface expression of $\alpha$-amino-3-hydroxy-5-methyl-4isoxazolepropionic (AMPA) receptors. In support of these findings, it was established subsequently by Stellwagen et al. (2005) that the up-regulation of AMPA receptors by TNF is mediated through TNFR1 and phosphatidylinositol 3 (PI3) kinase-dependent processes. Interestingly, it was also determined by these researchers, that TNF simultaneously causes a decrease in synaptic inhibition via endocytosis of $\mathrm{GABA}_{\mathrm{A}}$ receptors (Stellwagen et al., 2005). Such findings support a neuromodulatory role for TNF within the brain and suggest a possible role for TNF in synaptic plasticity.

The stability and cycling of AMPA receptors at synapses has been shown to be an essential process in both LTP and LTD (Malenka and Bear, 2004; Malenka and Nicoll, 1999). Since TNF- $\alpha$ has been shown to up-regulate AMPA receptors (Beattie et al., 2002; Stellwagen et al., 2005) it has been postulated that TNF might serve an essential function in Hebbian synaptic plasticity and possibly learning and memory. Research by Tancredi et al. (1992) and Cunningham et al. (1996), but not others (i.e. Stellwagen and Malenka, 2006) have demonstrated that pathophysiological levels of TNF inhibit LTP in the dentate gyrus of rat hippocampal slices. In support of these findings, Butler et al. (2004) determined that the inhibitory effect of TNF on LTP is a biphasic response. More specifically, their research demonstrated that the inhibition of early phase LTP by TNF is dependent on a p38 mitogen-activated protein kinase process, whereas, late phase LTP inhibition is p38 MAPK-independent (Butler et al., 2004). Subsequent research (i.e. Cumiskey et al., 2007) has further shown that TNF inhibition of LTP is dependent on TNF-R1 and mGlu5receptor activation. In addition to these findings, Albensi and Mattson (2000) have demonstrated a role for endogenous TNF and NF- $\kappa \mathrm{B}$ signalling in LTD induction. Unlike the exogenous studies previously mentioned, the results from Albensi and Mattson (2000) provide evidence for a TNF-mediated physiological role in synaptic plasticity.

Although these results support a role for TNF in LTP and LTD, alternative suggestions have been made (Stellwagen and Malenka, 2006). In a series of elegant experiments, Stellwagen and Malenka (2006) demonstrated that endogenous glial-derived TNF is critical for homeostatic synaptic scaling. In particular, it was shown that during prolonged inactivity TNF shifts neurons towards more excitation and less inhibition (Stellwagen and Malenka, 2006) (see Fig. 2). Such findings support recent studies that glial cells play an essential role in neuronal processing, synaptic integration and synaptogenesis (Bains and Oliet, 2007; Bezzi and Volterra, 2001; Halassa et al., 2007a; Slezak and Pfrieger, 2003; Turrigiano, 2006; Vesce et al., 2001). Although poorly understood, glial modulation of neuronal activity appears to involve cytokines such as TNF and BDNF (see Halassa et al., 2007b; Rutherford et al., 1998; Swanwick et al., 2006; Volterra et al., 2002 for details). Moreover, there is now reason to believe that glial-neuronal homeostatic synaptic plasticity mediated by TNF plays an essential role in learning and memory (Bains and Oliet, 2007; Turrigiano, 2006, 2007). The clarification of TNF's participation in synaptic plasticity is not only warranted, but might otherwise explain cognitive-behavioural findings (see Table 1 for details) that disruption of these physiological processes leads to cognitive impairment.

As recently shown by this research group the presence of TNF, in mice, under immunologically non-challenged conditions is essential for normal functions of memory and learning (Baune et al., 2008). Cognitive impairment has also been demonstrated in transgenic mice over-expressing TNF (Aloe et al., 1999; Campbell et al., 1997; Fiore et al., 1996, 2000). This TNF over-expressionassociated decline in cognitive function might relate to changes in synaptic plasticity (Small, 2008; Tobinick and Gross, 2008a) and/or possibly decreased NGF levels (Fiore et al., 2000); which has been shown to impair long-term potentiation (Kelly et al., 1998, 2000) and cause neurodegeneration (Capsoni and Cattaneo, 2006; Capsoni et al., 2000, 2002). Future research is, therefore, needed 


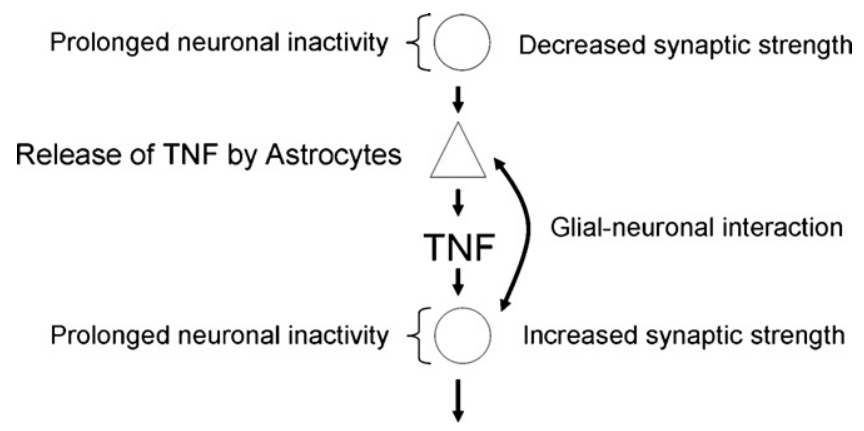

SYNAPTIC SCALING

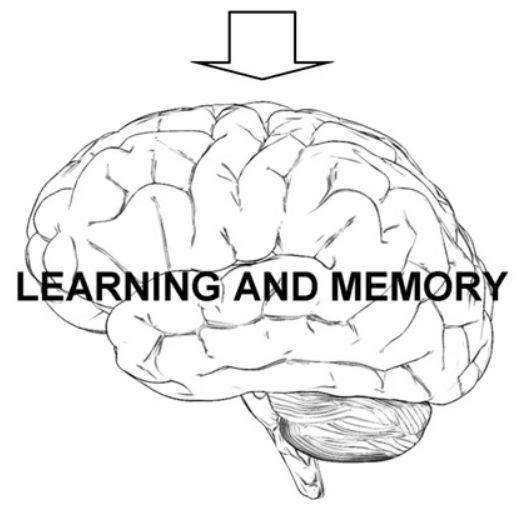

Fig. 2. Schematic illustration of the involvement of TNF in synaptic scaling a nonHebbian form of synaptic plasticity. In brief, a prolonged period of neuronal inactivity leads to a decrease in synaptic strength, which triggers, via glial-neuronal communication, the release of TNF by astrocytes. In a reciprocal fashion, the released TNF by astrocytes influences the activity of the post-synaptic neuron resulting in an increase in synaptic strength. Collectively, this helps to maintain neuronal activity 'synaptic scaling' and learning and memory functions.

to unravel the participation of TNF in synaptic plasticity and cognitive function during health and disease.

\subsection{Other potential mechanisms by which cytokines might mediate cognitive processes}

Based on the pleiotrophic biological properties of cytokines, it is plausible that cytokines might influence synaptic plasticity and/or cognitive processes via alternative mechanisms then those stated above (see Fig. 3 for schematic illustration). For instance, proinflammatory cytokines, such as IL- 1 and TNF have been shown to activate small G-proteins such as, Ras, Rho, Rac and Rap1 (MacEwan, 2002a,b; Williams et al., 2008). Of particular interest in regards to cytokine-mediated cognition is recent evidence that glia-derived TNF inhibits neurite outgrowth and branching by activating RhoA in neurons (Neumann et al., 2002). Since synaptogenesis and dendritic branching serve an essential role in synaptic plasticity and learning and memory processes (Muller et al., 2000, 2002; Remy and Spruston, 2007), TNF might exert profound effects on cognitive functioning through such mechanisms. Although this has not be well studied, recent evidence has implicated Rho in mental retardation, synaptic plasticity (i.e. synaptogenesis and dendritic branching) and cognition (Chechlacz and Gleeson, 2003; Govek et al., 2005; Meng et al., 2005; Newey et al., 2005; Ramakers, 2002). Future research is, therefore, needed to clarify the role in which cytokines, such as TNF, might play in synaptogenesis, dendritic branching and how these processes might relate to Rho activation and cognitive processes.

Other evidence has suggested that $\mathrm{P} 2 \mathrm{x} 7$ receptors ( $\mathrm{P} 2$ purinergic receptors) serve an important role in neuronal-glia communication and cytokine-mediated processes within the brain (Bennett, 2007; Lister et al., 2007; Sperlagh et al., 2006). Purinergic receptors are divided into two major families, which bind adenosine (P1 receptors), and ATP, ADP, UTP or UDP (P2 receptors). P2 purinergic receptors are further divided into ligand-gated channel or ionotropic receptors (P2X receptors) and G-protein coupled receptors (P2Y receptors). In particular, $\mathrm{P} 2 \mathrm{X} 7$ has been recognized as an important receptor for several inflammatory molecules, such as IL-1, IL-6 and TNF. In particular, it is believed that $\mathrm{P} 2 \mathrm{x} 7$ receptors play a key role in the brain cytokine response to immune stimuli that leads to sickness behaviour and possibly depression and/or cognitive dysfunction (Bennett, 2007; Mingam et al., 2008). Future research should also be directed at elucidating such possible mechanisms and pathways in both disease and health.

\subsection{Other cytokines potentially influencing cognitive function}

\subsubsection{Alpha1-antichymotrypsin (ACT)}

Biochemical and genetic studies indicate that ACT is important in the pathogenesis of Alzheimer's disease. In a study using several lines of transgenic/knockout mice it was shown that human ACT separately and synergistically with ApoE facilitate both diffuse A beta immunoreactive and fibrillar amyloid deposition, thus promoting cognitive impairment in aged PDAPP(V717F) mice. The degree of cognitive impairment was correlated with the ApoEand ACT-dependent hippocampal amyloid burden (Nilsson et al., 2004). Further supportive data for the involvement of ACT in cognitive decline stems from a population-based study showing that the serum inflammatory protein alpha1-antichymotrypsin was associated with cognitive decline in older persons (Dik et al., 2005).

In a clinical genetic study among patients with a clinical diagnosis of probable AD and patients with early onset AD, the ACT gene appeared to influence the early clinical development of the disease and the interaction of the ACT and ApoE genes affected clinical progression of AD (Licastro et al., 2005). Interestingly, in a study among 108 patients with late onset $A D$, the authors report an association between the ACT polymorphisms but they failed to show an association between ACT serum levels and ACT polymorphism as well as a correlation between ACT serum levels and cognitive function (Mcllroy et al., 2000).

In summary, the data suggest consistent genetic findings of ACT polymorphism effects on cognitive function in AD in human which is in line with results from some animal studies; however no information is available to date on the direct involvement of ACT in molecular mechanisms of learning and memory.

\subsection{Interferon-gamma (IFN-gamma)}

In a recent animal study it was demonstrated that the cytokine IFN-gamma enhances neurogenesis in the dentate gyrus of adult mice and improves the spatial learning and memory performance of the animals (Baron et al., 2008). In older mice, the effect of IFNgamma is more pronounced in both wild-type mice and mice with Alzheimer's-like disease and is associated with neuroprotection (Baron et al., 2008). The authors suggest that limited amounts of IFN-gamma in the brain shape the neuropoietic milieu to enhance neurogenesis, possibly representing the normal function of the immune system in controlling brain inflammation and repair (Baron et al., 2008).

It is well known that cell renewal in the adult central nervous system is limited, and is blocked under inflammatory brain conditions. In an animal study it was demonstrated that neurogenesis of adult neural progenitor cells in mice are blocked by inflammation-associated microglia. Microglia activation occurred 


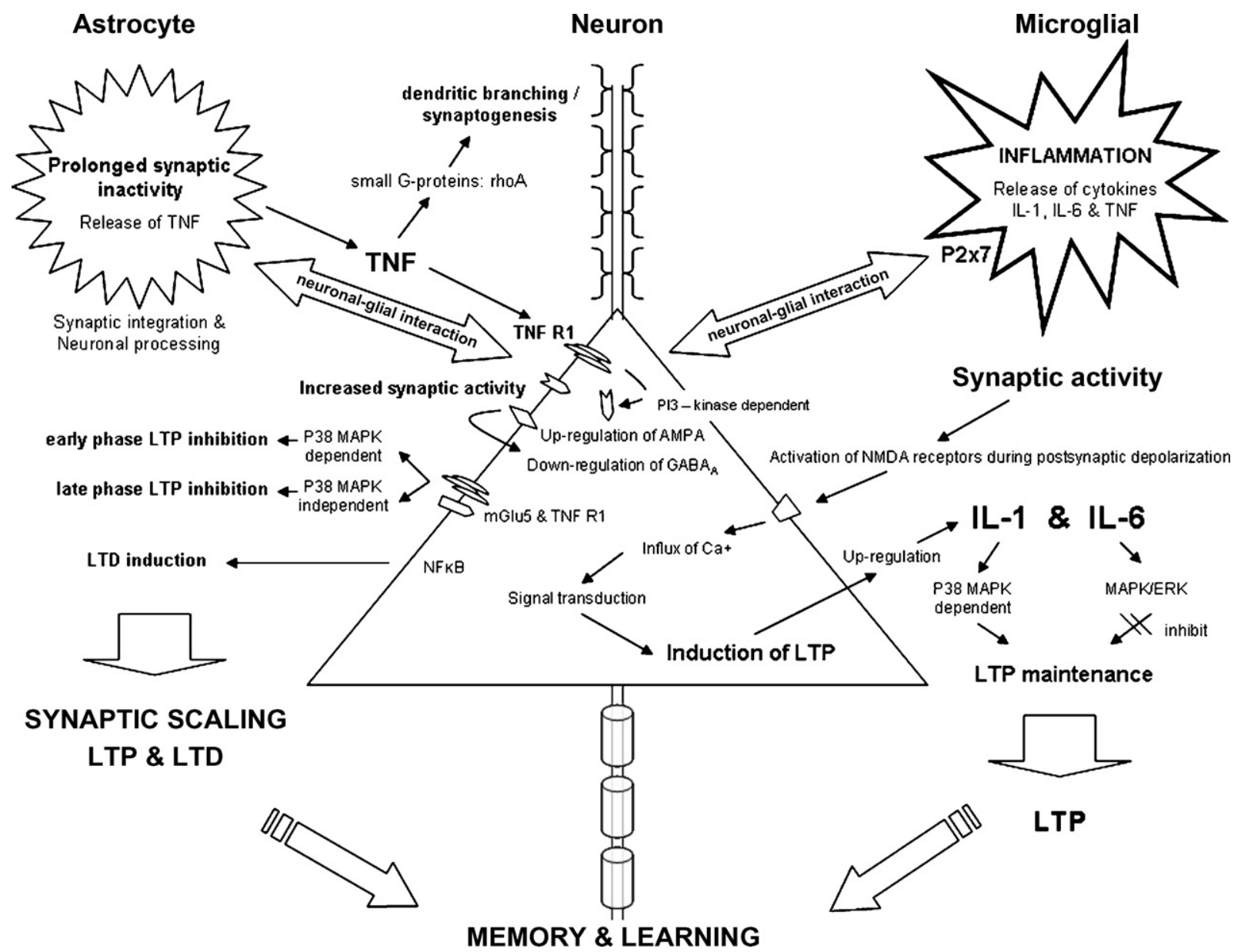

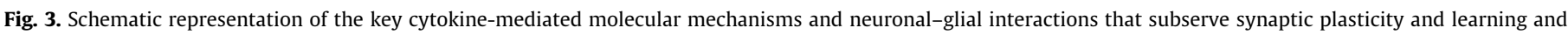

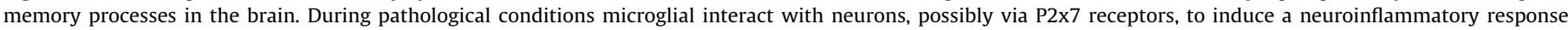

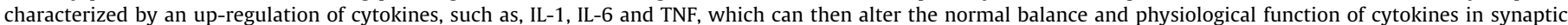

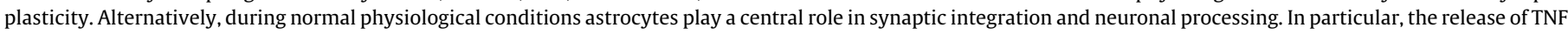

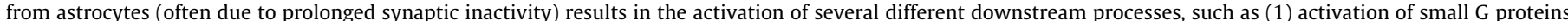

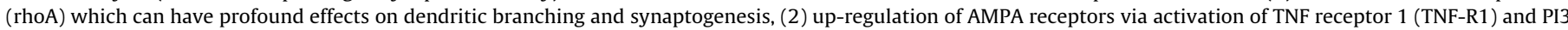

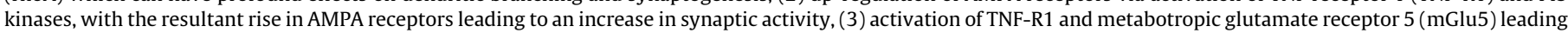

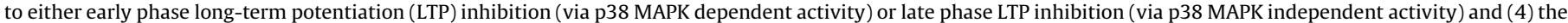

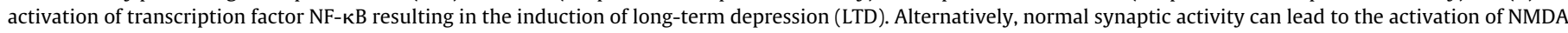

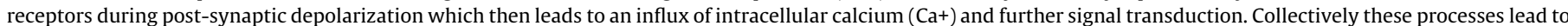

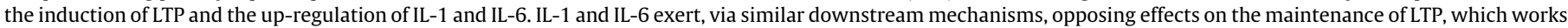

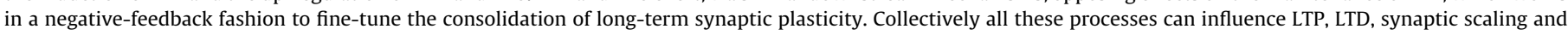
possibly other cellular mechanisms that subserve learning and memory.

through low level of IFN-gamma (Butovsky et al., 2006). Thus, it is suggested that IFN-gamma has the potential to stimulate neurogenesis, and the possibility to play a role in development and repair of the CNS (Kim et al., 2007). Moreover, since IFN-gamma is able to stimulate neurogenesis, a potential neural correlate of memory consolidation, it can be hypothesized that IFN-gamma has the potential ability to directly or indirectly subserve memory consolidation; however testing of this hypothesis is still outstanding.

Finally, clinical reports suggest that interferon (IFN) therapy is associated with neuropsychiatric side-effects including cognitive dysfunction and mood syndromes with varying rates of IFNinduced depression approaching up to $50 \%$ in recent studies (Valentine and Meyers, 2005).

\subsection{Interleukin-2 (IL-2)}

Relatively little direct evidence for the involvement of IL-2 in cognitive function is available to date. In a clinical study conducted among cancer patients, subcutaneous IL-2 was shown to impair spatial working memory and lower accuracy of planning abilities. In contrast, patients treated with IFN-alpha did not show any impairment in performance accuracy in these tasks but showed longer latencies in reaction time. Most of these early alterations persisted at the end of the first month of treatment without any obvious sign of worsening (Capuron et al., 2001).

The neurotoxic effects of IL- 2 in the above human study are supported by findings from animal research which showed that IL2 gene deletion alters the neuroimmunological status of the mouse hippocampus through a dysregulation of cytokines produced by CNS cells associated with increased hippocampal neurogenesis in male mice (Beck et al., 2005b).

\subsection{Cytokine signalling pathways in the injured brain}

Only limited evidence on the manipulations of the cytokines induced effects on cognition through pharmacological interventions has emerged over the past 10 years. In an experimental study, the effect of systemic administration of human recombinant 
interleukin-1 receptor antagonist (rhIL-1ra) on behavioral outcome was evaluated after brain injury in Sprague-Dawley rats (Sanderson et al., 1999). Postinjury administered high-dose rhIL1 ra significantly attenuated posttraumatic neuronal loss in the injured hippocampal CA3 region, dentate hilus, and cortex but impaired recovery of motor function at 7 days after trauma. In addition, postinjury administration of rhIL-1ra significantly attenuated cognitive deficits. These results suggest that inhibitors of cytokine pathways may be therapeutically useful for the treatment of brain trauma. Applying a similar animal study design this time using monoclonal antibodies ( $\mathrm{mAB}$ ), it was found that the treatment with either TNF- or IL-6-mAB had no effect on neurological motor, cognitive function or brain edema during the first post-injury week (Marklund et al., 2005). Studies using other than vascular models of cognition show that anti-TNF treatment of humans with Alzheimer's disease may lead to rapid cognitive improvement. However, it is unclear from this human study which TNF receptor mediated the improvement (Tobinick, 2007; Tobinick et al., 2006; Tobinick and Gross, 2008b).

Antagonistic effects of celecoxib, a selective cycloxygenase-2 (COX-2) inhibitor, on age-dependent increased cytokine expressions of IL-1beta and TNF in the hippocampus in the aging rat were investigated (Casolini et al., 2002). Since the chronic oral treatment with celecoxib was able to contrast the age-dependent increase in hippocampal levels of pro-inflammatory markers and circulating anti-inflammatory corticosterone (provided that intervention started at an early stage of aging), the results suggest a preventive potential of COX-2 inhibitors. However, it is still speculative that age-related impairments in cognitive ability may be ameliorated as cognition-like behaviour was not assessed in this animal study (Casolini et al., 2002).

Cytokine effects can also interact with receptors of other brain systems mediating disease states such as pain. In an animal study investigating the role of peripheral groups I and II metabotropic glutamate receptors (mGluRs) in interleukin-1beta (IL-1beta)induced mechanical allodynia in the orofacial area, it was found that the peripheral group I mGluR antagonists blocked the IL1beta-induced mechanical allodynia, while peripheral group II mGluR agonists produced anti-allodynic effects on IL-1betainduced mechanical allodynia in the orofacial area of rats (Ahn et al., 2005).

The limited studies to date on cytokine receptor involvement in cognitive function in humans and animal models indicate the need for further research covering a larger range of cytokines as well as inflammatory diseases to enhance the understanding of the underlying mechanisms, but also with the aim to translate the research into clinical pharmacological applications for the treatment of neuropsychiatric diseases characterized by cognitive impairment such as dementia and depression.

\section{Limitations and future research}

The research on cytokine involvement with cognitive function and cognitive impairment leading to the proposed cytokine model of cognitive function is largely based on animal studies as well as clinical studies in humans as evaluated in this review. While animal studies help to understand the molecular and cellular mechanisms of learning and memory and cognitive function, clinical studies contribute to the understanding of cognitive impairment in humans with circumscribed diseases such as dementia. The major limitations of the research on this topic are the relatively few cytokines for which sufficient evidence of their molecular and cellular effects related to cognitive function and/or learning and memory is readily available and secondly the largely missing link of translational research from basic science to clinical applications. This is evidenced by the few published studies in humans applying the principle of cytokine blockade in order to improve cognitive performance as demonstrated with anti-TNF treatment in dementia (Tobinick et al., 2006).

The research on cytokines in cognitive function in humans is also limited by the difficulty to make use of pharmacological receptor blockade of cytokine effects involved in cognitive function. The development of receptor specific antibodies for the use in humans without causing significant side-effects and the translation from animal research would hold potential for the development of new treatments for various neuropsychiatric conditions related with cognitive decline. Finally, the translation of animal research assessing cognition-like behaviour to more complex human behaviour is a challenge in itself. Although the animal models provide reliable and valid cognitive measures, neurospychological concepts in humans such as word fluency, executive function and consciousness are difficult to capture or represent in animal models. However, future research on cytokines in cognitive function would benefit from an approach in which line of evidence for cytokine effects on cognitive function is created including animal models and clinical applications covering molecular cellular and clinical studies.

\section{Clinical implications and conclusions}

There is now considerable evidence to suggest that cytokines mediate essential nervous system functions during health that lie outside their functions in traditional immune and inflammatory processes (Bauer et al., 2007; Pickering and O'Connor, 2007; Vitkovic et al., 2000a; Viviani et al., 2007). In particular, data suggests that pro-inflammatory cytokines, such as IL-1, IL-6 and TNF, serve a specific function in synaptic plasticity and cognitive processes. Additional evidence is seen for effects of ACT and IFGgamma on cognitive function. Further clarification and future inclusion of other potential candidates of the suggested cytokinemediated model of cognition will not only provide better understanding of these physiological processes, but might also have direct relevance to the understanding of pathological changes seen in certain neuropsychiatric diseases. For instance, as suggested by Small $(2004,2008)$, the progression of Alzheimer's disease might be driven by exaggerated, TNF-mediated, synaptic scaling during prolonged inactivity caused by $\beta$-amyloid. It must be emphasized here, that it is the physiological function of TNF in synaptic scaling (i.e. thought to subserve cognitive processes) and not inflammatory or pathophysiological processes of TNF that is postulated to be driving disease progression. Although it remains to be clarified, clinical data obtained by Tobinick (2007), Tobinick et al. (2006) and Tobinick and Gross (2008a) suggests that the rapid cognitive improvement seen in Alzheimer's disease patients receiving antiTNF treatment (i.e. perispinal administration of etanercept) maybe the result of reversed excess TNF-mediated synaptic plasticity dysregulation. Future research aimed at elucidating the role in which TNF plays in normal synaptic plasticity might lead to better disease understanding and therapeutic intervention.

Depression might also represent an exaggerated form of cytokine-mediated behaviour, in that cytokines naturally exert a normal role in the brain that manifests as 'sickness behaviour' in disease models with over-expressed cytokines (Dantzer et al., 2008). This natural behavioural change is both adaptive and physiological, but during prolonged inflammation and/or psychological stress might lead to the pathogenesis of depression. The 'hijacking' of these physiological processes during disease might also explain the high comorbidity between neurodegenerative diseases and depression (Caballero et al., 2006) and why depression is a risk factor for neurodegenerative diseases (McDonald et al., 2003; Ownby et al., 2006). The clinical application of anti-inflammatory treatments 
in depression is still outstanding, although the present basic science data are suggestive of such a translation research approach.

Finally, the clarification and understanding of the physiological functions of cytokines within the brain might also provide insight into age-associated cognitive decline (Bodles and Barger, 2004; Griffin et al., 2006; Lynch, 1998; Maher et al., 2005; Nolan et al., 2005).

In summary, the review provides evidence that cytokines mediate essential nervous system functions during health that lie outside their functions in traditional immune and inflammatory processes. In particular, the cytokines IL-1eta, IL-6 and TNF-alpha hold biological features at the molecular level, such as synaptic plasticity, neurogenesis and neuromodulation, and at cellular mechanisms subserving learning, memory and cognition under physiological conditions. These cytokine-mediated cognitive processes have significant implications in healthy states as well as in the long-term development and pathogenesis of specific neuropsychiatric disorders such as major depression and dementia.

\section{References}

Abbott, L.F., Nelson, S.B., 2000. Synaptic plasticity: taming the beast. Nat. Neurosci. 3 (Suppl.), 1178-1183.

Ahn, D.K., Kim, K.H., et al., 2005. Role of peripheral group I and II metabotropic glutamate receptors in IL-1beta-induced mechanical allodynia in the orofacial area of conscious rats. Pain 118 (1-2), 53-60.

Albensi, B.C., Mattson, M.P., 2000. Evidence for the involvement of TNF and NFkappaB in hippocampal synaptic plasticity. Synapse 35 (2), 151-159.

Allan, S.M., Tyrrell, P.J., et al., 2005. Interleukin-1 and neuronal injury. Nat. Rev. Immunol. 5 (8), 629-640.

Aloe, L., Properzi, F., et al., 1999. Learning abilities, NGF and BDNF brain levels in two lines of TNF-alpha transgenic mice, one characterized by neurological disorders, the other phenotypically normal. Brain Res. 840 (1-2), 125-137.

Anisman, H., Merali, Z., et al., 2008. Neurotransmitter, peptide and cytokine processes in relation to depressive disorder: comorbidity between depression and neurodegenerative disorders. Prog. Neurobiol. (1), 1-74.

Avital, A., Goshen, I., et al., 2003. Impaired interleukin-1 signaling is associated with deficits in hippocampal memory processes and neural plasticity. Hippocampus 13 (7), 826-834.

Bains, J.S., Oliet, S.H., 2007. Glia: they make your memories stick! Trends Neurosci. 30 (8), 417-424.

Balschun, D., Wetzel, W., et al., 2004. Interleukin-6: a cytokine to forget. FASEB J. 18 (14), 1788-1790.

Baron, R., Nemirovsky, A., et al., 2008. IFN-gamma enhances neurogenesis in wildtype mice and in a mouse model of Alzheimer's disease. FASEB J. 22 (8), $2843-$ 2852.

Baud, V., Karin, M., 2001. Signal transduction by tumor necrosis factor and it relatives. Trends Cell Biol. 11 (9), 372-377.

Bauer, S., Kerr, B.J., et al., 2007. The neuropoietic cytokine family in development, plasticity, disease and injury. Nat. Rev. 8 (3), 221-232.

Baune, B.T., Ponath, G., et al., 2008a. Association between IL-8 cytokine and cognitive performance in an elderly general population-The MEMO-Study. Neurobiol. Aging 29 (6), 937-944.

Baune, B.T., Ponath, G., et al., 2008b. Association between genetic variants of IL1beta, IL- 6 and TNF-alpha cytokines and cognitive performance in the elderly general population of the MEMO-study. Psychoneuroendocrinology 33 (1), 6876.

Baune, B.T., Wiede, F., et al., 2008. Cognitive dysfunction in mice deficient for TNFand its receptors. Am. J. Med. Genet. B Neuropsychiatr. Genet. 147B, 1056-1064.

Beattie, E.C., Stellwagen, D., et al., 2002. Control of synaptic strength by glial TNFalpha. Science 295 (5563), 2282-2285.

Beck Jr., R.D., King, M.A., et al., 2005a. IL-2 deficiency results in altered septal and hippocampal cytoarchitecture: relation to development and neurotrophins. J. Neuroimmunol. 160 (1-2), 146-153.

Beck Jr., R.D., King, M.A., et al., 2002. Alterations in septohippocampal cholinergic neurons resulting from interleukin-2 gene knockout. Brain Res. 955 (1-2), 1623.

Beck Jr., R.D., Wasserfall, C., et al., 2005b. Changes in hippocampal IL-15, related cytokines, and neurogenesis in IL-2 deficient mice. Brain Res. 1041 (2), 223230.

Bellinger, F.P., Madamba, S., et al., 1993. Interleukin 1 beta inhibits synaptic strength and long-term potentiation in the rat CA1 hippocampus. Brain Res. 628 (1-2), 227-234.

Ben Menachem-Zidon, O., Goshen, I., et al., 2007. Intrahippocampal transplantation of transgenic neural precursor cells overexpressing interleukin-1 receptor antagonist blocks chronic isolation-induced impairment in memory and neurogenesis. Neuropsychopharmacology (9), 2251-2262.

Bennett, M.R., 2007. Synaptic P2X7 receptor regenerative-loop hypothesis for depression. Aust. N.Z. J. Psychiatry 41 (7), 563-571.
Bezzi, P., Volterra, A., 2001. A neuron-glia signalling network in the active brain. Curr. Opin. Neurobiol. 11 (3), 387-394.

Bitsch, A., Kuhlmann, T., et al., 2000. Tumour necrosis factor alpha mRNA expression in early multiple sclerosis lesions: correlation with demyelinating activity and oligodendrocyte pathology. Glia 29, 366-375.

Blatteis, C.M., 1990. Neuromodulative actions of cytokines. Yale J. Biol. Med. 63 (2) 133-146.

Bodles, A.M., Barger, S.W., 2004. Cytokines and the aging brain-what we don't know might help us. Trends Neurosci. 27 (10), 621-626.

Bosshardt, S., Schmidt, C.F., et al., 2005. Effects of memory consolidation on human hippocampal activity during retrieval. Cortex 41 (4), 486-498.

Braida, D., Sacerdote, P., et al., 2004. Cognitive function in young and adult IL (interleukin)-6 deficient mice. Behav. Brain Res. 153 (2), 423-429.

Brennan, F.X., Beck, K.D., et al., 2003. Low doses of interleukin-1beta improve the leverpress avoidance performance of Sprague-Dawley rats. Neurobiol. Learn Mem. 80 (2), 168-171.

Bruel-Jungerman, E., Laroche, S., et al., 2005. New neurons in the dentate gyrus are involved in the expression of enhanced long-term memory following environmental enrichment. Eur. J. Neurosci. 21 (2), 513-521.

Bruel-Jungerman, E., Davis, S., et al., 2006. Long-term potentiation enhances neurogenesis in the adult dentate gyrus. J. Neurosci. 26, 5888-5893.

Bruel-Jungerman, E., Davis, S., et al., 2007a. Brain plasticity mechanisms and memory: a party of four. Neuroscientist 13 (5), 492-505.

Bruel-Jungerman, E., Rampon, C., et al., 2007b. Adult hippocampal neurogenesis, synaptic plasticity and memory: facts and hypotheses. Rev. Neurosci. 18 (2), 93-114.

Buckner, R.L., 2003. Functional-anatomic correlates of control processes in memory. J. Neurosci. 23 (10), 3999-4004.

Burrone, J., Murthy, V.N., 2003. Synaptic gain control and homeostasis. Curr. Opin. Neurobiol. 13 (5), 560-567.

Butler, M.P., O'Connor, J.J., et al., 2004. Dissection of tumor-necrosis factor-alpha inhibition of long-term potentiation (LTP) reveals a p38 mitogen-activated protein kinase-dependent mechanism which maps to early-but not late-phase LTP. Neuroscience 124 (2), 319-326.

Butovsky, O., Ziv, Y., et al., 2006. Microglia activated by IL-4 or IFN-gamma differentially induce neurogenesis and oligodendrogenesis from adult stem/ progenitor cells. Mol. Cell. Neurosci. 31 (1), 149-160.

Caballero, J., Hitchcock, M., et al., 2006. Long-term effects of antidepressants on cognition in patients with Alzheimer's disease. J. Clin. Pharm. Ther. 31 (6), 593-598.

Campbell, I.L., Stalder, A.K., et al., 1997. Transgenic models to assess the pathogenic actions of cytokines in the central nervous system. Mol. Psychiatry 2(2), 125-129.

Capsoni, S., Cattaneo, A., 2006. On the molecular basis linking nerve growth factor (NGF) to Alzheimer's disease. Cell. Mol. Neurobiol. 26 (4-6), 619-633.

Capsoni, S., Giannotta, S., et al., 2002. Beta-amyloid plaques in a model for sporadic Alzheimer's disease based on transgenic anti-nerve growth factor antibodies. Mol. Cell. Neurosci. 21 (1), 15-28.

Capsoni, S., Ugolini, G., et al., 2000. Alzheimer-like neurodegeneration in aged antinerve growth factor transgenic mice. Proc. Natl. Acad. Sci. U.S.A. 97 (12), 6826-6831.

Capuron, L., Dantzer, R., 2003. Cytokines and depression: the need for a new paradigm. Brain Behav. Immun. 17 (Suppl. 1), S119-S124.

Capuron, L., Ravaud, A., et al., 2001. Timing and specificity of the cognitive changes induced by interleukin-2 and interferon-alpha treatments in cancer patients. Psychosom. Med. 63 (3), 376-386.

Casolini, P., Catalani, A., et al., 2002. Inhibition of COX-2 reduces the age-dependent increase of hippocampal inflammatory markers, corticosterone secretion, and behavioral impairments in the rat. J. Neurosci. Res. 68 (3), 337-343.

Chechlacz, M., Gleeson, J.G., 2003. Is mental retardation a defect of synapse structure and function? Pediatr. Neurol. 29 (1), 11-17.

Chen, G., Goeddel, D.V., 2002. TNF-R1 signaling: a beautiful pathway. Science 296, 1634-1635.

Cheng, B., Christakos, S., et al., 1994. Tumor necrosis factors protect neurons against metabolic-excitotoxic insults and promote maintenance of calcium homeostasis. Neuron 12 (1), 139-153.

Colotta, F., Dower, S.K., et al., 1994. The type II 'decoy' receptor: a novel regulatory pathway for interleukin 1 . Immunol. Today 15 (12), 562-566.

Colotta, F., Re, F., et al., 1993. Interleukin-1 type II receptor: a decoy target for IL-1 that is regulated by IL-4. Science 261 (5120), 472-475.

Coogan, A.N., O'Neill, L.A., et al., 1999. The P38 mitogen-activated protein kinase inhibitor SB203580 antagonizes the inhibitory effects of interleukin-1beta on long-term potentiation in the rat dentate gyrus in vitro. Neuroscience 93 (1), 57-69.

Cumiskey, D., Butler, M.P., et al., 2007. Evidence for a role for the group I metabotropic glutamate receptor in the inhibitory effect of tumor necrosis factor-alpha on long-term potentiation. Brain Res. 1136 (1), 13-19.

Cunningham, A.J., Murray, C.A., et al., 1996. Interleukin-1 beta (IL-1 beta) and tumour necrosis factor (TNF) inhibit long-term potentiation in the rat dentate gyrus in vitro. Neurosci. Lett. 203 (1), 17-20.

Dantzer, R., O'Connor, J.C., et al., 2008. From inflammation to sickness and depression: when the immune system subjugates the brain. Nat. Rev. 9 (1), 46-56.

Deak, T., 2007. From hippocampus to dorsal horn: the pervasive impact of IL-1 on learning and memory spans the length of the neuroaxis. Brain Behav. Immun. 21 (6), 746-747. 
Depino, A.M., Alonso, M., et al., 2004. Learning modulation by endogenous hippocampal IL-1: blockade of endogenous IL-1 facilitates memory formation. Hippocampus 14 (4), 526-535.

Dik, M.G., Jonker, C., et al., 2005. Serum inflammatory proteins and cognitive decline in older persons. Neurology 64 (8), 1371-1377.

Drapeau, E., Mayo, W., et al., 2003. Spatial memory performances of aged rats in the water maze predict levels of hippocampal neurogenesis. Proc. Natl. Acad. Sci. U.S.A. 100 (24), 14385-14390.

Drapeau, E., Montaron, M.F., et al., 2007. Learning-induced survival of new neurons depends on the cognitive status of aged rats. J. Neurosci. 27 (22), 6037-6044.

Dupret, D., Fabre, A., et al., 2007. Spatial learning depends on both the addition and removal of new hippocampal neurons. PLoS Biol. 5 (8), e214.

Echegoyen, J., Neu, A., et al., 2007. Homeostatic plasticity studied using in vivo hippocampal activity-blockade: synaptic scaling, intrinsic plasticity and agedependence. PLoS ONE 2 (1), e700.

Fiore, M., Angelucci, F., et al., 2000. Learning performances, brain NGF distribution and NPY levels in transgenic mice expressing TNF-alpha. Behav. Brain Res. 112 (1-2), 165-175.

Fiore, M., Probert, L., et al., 1996. Neurobehavioral alterations in developing transgenic mice expressing TNF-alpha in the brain. Brain Behav. Immun. 10 (2), 126-138.

Gemma, C., Catlow, B., et al., 2007. Early inhibition of TNFalpha increases 6hydroxydopamine-induced striatal degeneration. Brain Res. 1147, 240-247.

Godbout, J.P., Johnson, R.W., 2004. Interleukin-6 in the aging brain. J. Neuroimmunol. 147 (1-2), 141-144

Goshen, I., Kreisel, T., et al., 2007a. Brain interleukin-1 mediates chronic stressinduced depression in mice via adrenocortical activation and hippocampal neurogenesis suppression. Mol. Psychiatry (7), 717-728.

Goshen, I., Kreisel, T., et al., 2007b. A dual role for interleukin-1 in hippocampaldependent memory processes. Psychoneuroendocrinology 32 (8-10), 11061115.

Govek, E.E., Newey, S.E., et al., 2005. The role of the Rho GTPases in neuronal development. Genes Dev. 19 (1), 1-49.

Grau, J.W., Crown, E.D., et al., 2006. Instrumental learning within the spinal cord: underlying mechanisms and implications for recovery after injury. Behav. Cogn. Neurosci. Rev. 5 (4), 191-239.

Griffin, R., Nally, R., et al., 2006. The age-related attenuation in long-term potentiation is associated with microglial activation. J. Neurochem. 99 (4), 1263-1272.

Gurwitz, D., 1997. Interleukin-6 attenuation of scopolamine-induced amnesia: plausible involvement of cholinergic neuronal survival. Neuroreport 8 (16) i-ii.

Halassa, M.M., Fellin, T., et al., 2007a. The tripartite synapse: roles for gliotransmission in health and disease. Trends Mol. Med. 13 (2), 54-63.

Halassa, M.M., Fellin, T., et al., 2007b. Synaptic islands defined by the territory of a single astrocyte. J. Neurosci. 27 (24), 6473-6477.

Harding, D., Brull, D., et al., 2005. Variation in the interleukin-6 gene is associated with impaired cognitive development in children born prematurely: a preliminary study. Pediatr. Res. 58 (1), 117-120.

He, P., Zhong, Z., et al., 2007. Deletion of tumor necrosis factor death receptor inhibits amyloid \{beta\} generation and prevents learning and memory deficits in Alzheimer's mice. J. Cell Biol. 178 (5), 829-841.

Hebb, D.O., 1949. The Organization of Behavior. Wiley, New York.

Hirano, T., Nakajima, K., et al., 1997. Signaling mechanisms through gp130: a model of the cytokine system. Cytokine Growth Factor Rev. 8 (4), 241-252.

Holmes, C., El-Okl, M., et al., 2003. Systemic infection, interleukin 1beta, and cognitive decline in Alzheimer's disease. J. Neurol. Neurosurg. Psychiatry 74 (6), 788-789.

Hopkins, S.J., Rothwell, N.J., 1995. Cytokines and the nervous system. I. Expression and recognition. Trends Neurosci. 18 (2), 83-88.

Hryniewicz, A., Bialuk, I., et al., 2007. Impairment of recognition memory in interleukin-6 knock-out mice. Eur. J. Pharmacol. 577 (1-3), 219-220.

Irwin, M.R., Miller, A.H., 2007. Depressive disorders and immunity: 20 years of progress and discovery. Brain Behav. Immun. 21 (4), 374-383.

Itzhak, Y., Achat-Mendes, C., 2004. Methamphetamine and MDMA (ecstasy) neurotoxicity: 'of mice and men'. IUBMB Life 56 (5), 249-255.

Jankowsky, J.L., Derrick, B.E., et al., 2000. Cytokine responses to LTP induction in the rat hippocampus: a comparison of in vitro and in vivo techniques. Learn. Mem. 7 (6), 400-412.

Jankowsky, J.L., Patterson, P.H., 1999. Cytokine and growth factor involvement in long-term potentiation. Mol. Cell. Neurosci. 14 (6), 273-286.

Kaneko, N., Kudo, K., et al., 2006. Suppression of cell proliferation by interferonalpha through interleukin-1 production in adult rat dentate gyrus. Neuropsychopharmacology 31 (12), 2619-2626.

Katsuki, H., Nakai, S., et al., 1990. Interleukin-1 beta inhibits long-term potentiation in the CA3 region of mouse hippocampal slices. Eur. J. Pharmacol. 181 (3), 323 326.

Kelly, A., Conroy, S., et al., 1998. Evidence that nerve growth factor plays a role in long-term potentiation in the rat dentate gyrus. Neuropharmacology 37 (4-5), 561-570.

Kelly, A., Maguire, C., et al., 2000. Deficits in nerve growth factor release and tyrosine receptor kinase phosphorylation are associated with age-related impairment in long-term potentiation in the dentate gyrus. Neuroscience 95 (2), 359-365.

Kim, S.J., Son, T.G., et al., 2007. Interferon-gamma promotes differentiation of neura progenitor cells via the JNK pathway. Neurochem. Res. 32 (8), 1399-1406.
Knowlton, B.J., Fanselow, M.S., 1998. The hippocampus, consolidation and on-line memory. Curr. Opin. Neurobiol. 8 (2), 293-296.

Koo, J.W., Duman, R.S., 2008. IL-1beta is an essential mediator of the antineurogenic and anhedonic effects of stress. Proc. Natl. Acad. Sci. U.S.A. 105 (2), 751-756.

Kronfol, Z., Remick, D.G., 2000. Cytokines and the brain: implications for clinical psychiatry. Am. J. Psychiatry 157 (5), 683-694.

Lepage, M., Habib, R., et al., 1998. Hippocampal PET activations of memory encoding and retrieval: the HIPER model. Hippocampus 8 (4), 313-322.

Li, A.J., Katafuchi, T., et al., 1997. Interleukin-6 inhibits long-term potentiation in rat hippocampal slices. Brain Res. 748 (1-2), 30-38.

Licastro, F., Chiappelli, M., et al., 2005. A new promoter polymorphism in the alpha1 -antichymotrypsin gene is a disease modifier of Alzheimer's disease. Neurobiol. Aging 26 (4), 449-453.

Lister, M.F., Sharkey, J., et al., 2007. The role of the purinergic P2X7 receptor in inflammation. J. Inflamm. (Lond.) 4, 5.

Lynch, G., 2000. Memory Consolidation and Long-term Potentiation, second ed. The MIT Press, Cambridge.

Lynch, G., Rex, C.S., et al., 2007. LTP consolidation: substrates, explanatory power, and functional significance. Neuropharmacology 52 (1), 12-23.

Lynch, M.A., 1998. Age-related impairment in long-term potentiation in hippocampus: a role for the cytokine, interleukin-1 beta? Prog. Neurobiol. 56 (5), 571-589.

Lynch, M.A., 2004. Long-term potentiation and memory. Physiol. Rev. 84 (1), $87-$ 136.

MacEwan, D.J., 2002a. TNF ligands and receptors-a matter of life and death. Br. J. Pharmacol. 135 (4), 855-875.

MacEwan, D.J., 2002b. TNF receptor subtype signalling: differences and cellular consequences. Cell Signal 14 (6), 477-492.

Maher, F.O., Nolan, Y., et al., 2005. Downregulation of IL-4-induced signalling in hippocampus contributes to deficits in LTP in the aged rat. Neurobiol. Aging 26 (5), 717-728.

Malenka, R.C., Bear, M.F., 2004. LTP and LTD: an embarrassment of riches. Neuron 44 (1), 5-21.

Malenka, R.C., Nicoll, R.A., 1999. Long-term potentiation-a decade of progress? Science 285 (5435), 1870-1874.

Marklund, N., Keck, C., et al., 2005. Administration of monoclonal antibodies neutralizing the inflammatory mediators tumor necrosis factor alpha and interleukin -6 does not attenuate acute behavioral deficits following experimental traumatic brain injury in the rat. Restor. Neurol. Neurosci. 23 (1), 31-42.

Marsland, A.L., Petersen, K.L., et al., 2006. Interleukin-6 covaries inversely with cognitive performance among middle-aged community volunteers. Psychosom. Med. 68 (6), 895-903.

McDonald, W.M., Richard, I.H., et al., 2003. Prevalence, etiology, and treatment of depression in Parkinson's disease. Biol. Psychiatry 54 (3), 363-375.

Mcllroy, S.P., Vahidassr, M.D., et al., 2000. Association of serum AACT levels and AACT signal polymorphism with late-onset Alzheimer's disease in Northern Ireland. Int. J. Geriatr. Psychiatry 15 (3), 260-266.

Meeter, M., Murre, J.M., 2005. Tracelink: a model of consolidation and amnesia. Cogn. Neuropsychol. 22 (5), 559-587.

Meng, J., Meng, Y., et al., 2005. Abnormal long-lasting synaptic plasticity and cognition in mice lacking the mental retardation gene Pak3. J. Neurosci. 25 (28), 6641-6650.

Mingam, R., De Smedt, V., et al., 2008. In vitro and in vivo evidence for a role of the P2X7 receptor in the release of IL-1 beta in the murine brain. Brain Behav. Immun. 22 (2), 234-244.

Monje, M.L., Toda, H., et al., 2003. Inflammatory blockade restores adult hippocampal neurogenesis. Science 302 (5651), 1760-1765.

Muller, D., Nikonenko, I., et al., 2002. LTP, memory and structural plasticity. Curr. Mol. Med. 2 (7), 605-611.

Muller, D., Toni, N., et al., 2000. Spine changes associated with long-term potentiation. Hippocampus 10 (5), 596-604.

Murray, C.A., Lynch, M.A., 1998. Evidence that increased hippocampal expression of the cytokine interleukin- 1 beta is a common trigger for age- and stress-induced impairments in long-term potentiation. J. Neurosci. 18 (8), 2974-2981.

Nadel, L., Moscovitch, M., 1997. Memory consolidation, retrograde amnesia and the hippocampal complex. Curr. Opin. Neurobiol. 7 (2), 217-227.

Neumann, H., Schweigreiter, R., et al., 2002. Tumor necrosis factor inhibits neurite outgrowth and branching of hippocampal neurons by a rho-dependent mechanism. J. Neurosci. 22 (3), 854-862.

Newey, S.E., Velamoor, V., et al., 2005. Rho GTPases, dendritic structure, and mental retardation. J. Neurobiol. 64 (1), 58-74.

Nilsson, L.N., Arendash, G.W., et al., 2004. Cognitive impairment in PDAPP mice depends on ApoE and ACT-catalyzed amyloid formation. Neurobiol. Aging 25 (9), 1153-1167.

Nolan, Y., Maher, F.O., et al., 2005. Role of interleukin-4 in regulation of age-related inflammatory changes in the hippocampus. J. Biol. Chem. 280 (10), 9354-9362.

Ownby, R.L., Crocco, E., et al., 2006. Depression and risk for Alzheimer disease: systematic review, meta-analysis, and metaregression analysis. Arch. Gen. Psychiatry 63 (5), 530-538.

Pan, W., Kastin, A., 2001. Upregulation of the transport system for TNFa at the blood-brain barrier. Arch. Physiol. Biochem. 109 (4), 350-353.

Perez-Otano, I., Ehlers, M.D., 2005. Homeostatic plasticity and NMDA receptor trafficking. Trends Neurosci. 28 (5), 229-238.

Perry, R.T., Collins, J.S., et al., 2001. The role of TNF and its receptors in Alzheimer's disease. Neurobiol. Aging 22 (6), 873-883. 
Pickering, M., Cumiskey, D., et al., 2005. Actions of TNF-alpha on glutamatergic synaptic transmission in the central nervous system. Exp. Physiol. 90 (5), $663-$ 670.

Pickering, M., O'Connor, J.J., 2007. Pro-inflammatory cytokines and their effects in the dentate gyrus. Prog. Brain Res. 163, 339-354.

Pollmacher, T., Haack, M., et al., 2002. Low levels of circulating inflammatory cytokines-do they affect human brain functions? Brain Behav. Immun. 16 (5), 525-532.

Pugh, C., Fleshner, M., et al., 2001. The immune system and memory consolidation: a role for the cytokine IL-1beta. Neurosci. Biobehav. Rev. 25 (1), 29-41.

Raison, C.L., Capuron, L., et al., 2006. Cytokines sing the blues: inflammation and the pathogenesis of depression. Trends Immunol. 27 (1), 24-31.

Ramakers, G.J., 2002. Rho proteins, mental retardation and the cellular basis of cognition. Trends Neurosci. 25 (4), 191-199.

Ransohoff, R.M., Benveniste, E.N. (Eds.), 2006. Cytokines and the CNS. Taylor \& Francis Group, New York

Re, F., Sironi, M., et al., 1996. Inhibition of interleukin-1 responsiveness by type II receptor gene transfer: a surface "receptor" with anti-interleukin-1 function. J. Exp. Med. 183 (4), 1841-1850.

Reichenberg, A., Yirmiya, R., et al., 2001. Cytokine-associated emotional and cognitive disturbances in humans. Arch. Gen. Psychiatry 58 (5), 445-452.

Remy, S., Spruston, N., 2007. Dendritic spikes induce single-burst long-term potentiation. Proc. Natl. Acad. Sci. U.S.A. 104 (43), 17192-17197.

Renart, A., Song, P., et al., 2003. Robust spatial working memory through homeostatic synaptic scaling in heterogeneous cortical networks. Neuron $38(3), 473-$ 485.

Rojo, L.E., Fernandez, J.A., et al., 2008. Neuroinflammation: implications for the pathogenesis and molecular diagnosis of Alzheimer's disease. Arch. Med. Res. 39 (1), 1-16.

Rosenberg, P.B., 2005. Clinical aspects of inflammation in Alzheimer's disease. Int. Rev. Psychiatry (Abingdon, Engl.) 17 (6), 503-514.

Ross, F.M., Allan, S.M., et al., 2003. A dual role for interleukin-1 in LTP in mouse hippocampal slices. J. Neuroimmunol. 144 (1-2), 61-67.

Rothwell, N.J., 1999. Annual review prize lecture cytokines-killers in the brain? J. Physiol. 514, 3-17.

Rothwell, N.J., Hopkins, S.J., 1995. Cytokines and the nervous system. II. Actions and mechanisms of action. Trends Neurosci. 18 (3), 130-136.

Rothwell, N.J., Loddick, S. (Eds.), 2002. Immune and Inflammatory Responses in the Nervous System. Molecular and Cellular Neurobiology Series. Oxford University Press, New York.

Rutherford, L.C., Nelson, S.B., et al., 1998. BDNF has opposite effects on the quantal amplitude of pyramidal neuron and interneuron excitatory synapses. Neuron 21 (3), 521-530.

Sanderson, K.L., Raghupathi, R., et al., 1999. Interleukin-1 receptor antagonist attenuates regional neuronal cell death and cognitive dysfunction after experimental brain injury. J. Cereb. Blood Flow Metab. 19 (10), 1118-1125.

Saxe, M.D., Battaglia, F., et al., 2006. Ablation of hippocampal neurogenesis impairs contextual fear conditioning and synaptic plasticity in the dentate gyrus. Proc. Natl. Acad. Sci. U.S.A. 103 (46), 17501-17506.

Saxe, M.D., Malleret, G., et al., 2007. Paradoxical influence of hippocampal neurogenesis on working memory. Proc. Natl. Acad. Sci. U.S.A. 104 (11), 4642-4646.

Schmidt, R., Schmidt, H., et al., 2002. Early inflammation and dementia: a 25-year follow-up of the Honolulu-Asia Aging Study. Ann. Neurol. 52 (2), 168-174.

Schneider, H., Pitossi, F., et al., 1998. A neuromodulatory role of interleukin-1beta in the hippocampus. Proc. Natl. Acad. Sci. U.S.A. 95 (13), 7778-7783.

Schram, M.T., Euser, S.M., et al., 2007. Systemic markers of inflammation and cognitive decline in old age. J. Am. Geriatr. Soc. 55 (5), 708-716.

Schwartz, M., Sivron, T., et al., 1994. Cytokines and cytokine-related substances regulating glial cell response to injury of the central nervous system. Prog. Brain Res. 103, 331-341.

Schwartz, M., Solomon, A., et al., 1991. Tumor necrosis factor facilitates regeneration of injured central nervous system axons. Brain Res. 545 (1-2), 334-338.

Sei, Y., Vitkovic, L., et al., 1995. Cytokines in the central nervous system: regulatory roles in neuronal function, cell death and repair. Neuroimmunomodulation 2 (3), 121-133.

Shaftel, S.S., Griffin, W.S., et al., 2008. The role of interleukin-1 in neuroinflammation and Alzheimer disease: an evolving perspective. J. Neuroinflamm. 5, 7.

Shors, T.J., Townsend, D.A., et al., 2002. Neurogenesis may relate to some but not all types of hippocampal-dependent learning. Hippocampus 12 (5), 578-584.

Slezak, M., Pfrieger, F.W., 2003. New roles for astrocytes: regulation of CNS synaptogenesis. Trends Neurosci. 26 (10), 531-535.

Small, D.H., 2004. Mechanisms of synaptic homeostasis in Alzheimer's disease. Curr. Alzheimer Res. 1 (1), 27-32.

Small, D.H., 2008. Network dysfunction in Alzheimer's disease: does synaptic scaling drive disease progression? Trends Mol. Med. 14 (3), 103-108.

Snyder, J.S., Kee, N., et al., 2001. Effects of adult neurogenesis on synaptic plasticity in the rat dentate gyrus. J. Neurophysiol. 85, 2423-2431.

Sperlagh, B., Vizi, E.S., et al., 2006. P2X7 receptors in the nervous system. Prog. Neurobiol. 78 (6), 327-346.
Spulber, S., Oprica, M., et al., 2008. Blunted neurogenesis and gliosis due to transgenic overexpression of human soluble IL-1ra in the mouse. Eur. J. Neurosci. 27 (3), 549-558.

Stellwagen, D., Beattie, E.C., et al., 2005. Differential regulation of AMPA receptor and GABA receptor trafficking by tumor necrosis factor-alpha. J. Neurosci. 25 (12), 3219-3228.

Stellwagen, D., Malenka, R.C., 2006. Synaptic scaling mediated by glial TNF-alpha. Nature 440 (7087), 1054-1059.

Swanwick, C.C., Murthy, N.R., et al., 2006. Activity-dependent scaling of GABAergic synapse strength is regulated by brain-derived neurotrophic factor. Mol. Cell. Neurosci. 31 (3), 481-492

Szelenyi, J., 2001. Cytokines and the central nervous system. Brain Res. Bull. 54 (4), 329-338.

Tancredi, V., D'Antuono, M., et al., 2000. The inhibitory effects of interleukin-6 on synaptic plasticity in the rat hippocampus are associated with an inhibition of mitogen-activated protein kinase ERK. J. Neurochem. 75 (2), 634-643.

Tancredi, V., D'Arcangelo, G., et al., 1992. Tumor necrosis factor alters synaptic transmission in rat hippocampal slices. Neurosci. Lett. 146 (2), 176-178.

Tobinick, E., 2007. Perispinal etanercept for treatment of Alzheimer's disease. Curr. Alzheimer Res. 4 (5), 550-552.

Tobinick, E., Gross, H., et al., 2006. TNF-alpha modulation for treatment of Alzheimer's disease: a 6-month pilot study. MedGenMed 8 (2), 25.

Tobinick, E.L., Gross, H., 2008a. Rapid cognitive improvement in Alzheimer's disease following perispinal etanercept administration. J. Neuroinflamm. 5, 2 .

Tobinick, E.L., Gross, H., 2008b. Rapid improvement in verbal fluency and aphasia following perispinal etanercept in Alzheimer's disease. BMC Neurol. 8, 27.

Turrigiano, G., 2007. Homeostatic signaling: the positive side of negative feedback. Curr. Opin. Neurobiol. 17 (3), 318-324.

Turrigiano, G.G., 1999. Homeostatic plasticity in neuronal networks: the more things change, the more they stay the same. Trends Neurosci. 22 (5), 221-227.

Turrigiano, G.G., 2006. More than a sidekick: glia and homeostatic synaptic plasticity. Trends Mol. Med. 12 (10), 458-460.

Tweedie, D., Sambamurti, K., et al., 2007. TNF-alpha inhibition as a treatment strategy for neurodegenerative disorders: new drug candidates and targets. Curr. Alzheimer Res. 4 (4), 378-385.

Valentine, A.D., Meyers, C.A., 2005. Neurobehavioral effects of interferon therapy. Curr. Psychiatry Rep. 7 (5), 391-395.

Vallieres, L., Campbell, I.L., et al., 2002. Reduced hippocampal neurogenesis in adult transgenic mice with chronic astrocytic production of interleukin-6. J. Neurosci. 22 (2), 486-492.

Van Wagoner, N., Oh, J.W., et al., 1999. IL6 production by astrocytes: autocrine regulation by IL-6 and the soluble IL-6 receptor. J. Neurosci. 19, 5236-5244.

Van Wagoner, N.J., Benveniste, E.N., 1999. Interleukin-6 expression and regulation in astrocytes. J. Neuroimmunol. 100 (1-2), 124-139.

Vesce, S., Bezzi, P., et al., 2001. Synaptic transmission with the glia. News Physiol. Sci. $16,178-184$

Vitkovic, L., Bockaert, J., et al., 2000a. Inflammatory" cytokines: neuromodulators in normal brain? J. Neurochem. 74 (2), 457-471.

Vitkovic, L., Konsman, J.P., et al., 2000b. Cytokine signals propagate through the brain. Mol. Psychiatry 5 (6), 604-615.

Viviani, B., Bartesaghi, S., et al., 2004. Cytokines role in neurodegenerative events. Toxicol. Lett. $149(1-3), 85-89$

Viviani, B., Gardoni, F., et al., 2007. Cytokines and neuronal ion channels in health and disease. Int. Rev. Neurobiol. 82, 247-263.

Volterra, A., Magistretti, P.J. (Eds.), 2002. The Tripartite Synapse: Glia in Synaptic Transmission. Oxford University Press, Oxford.

Wajant, H., Pfizenmaier, K., et al., 2003. Tumor necrosis factor signalling. Cell Death Differ. 10, 45-65.

Ward, L.D., Howlett, G.J., et al., 1994. High affinity interleukin-6 receptor is a hexameric complex consisting of two molecules each of interleukin-6, interleukin-6 receptor, and gp-130. J. Biol. Chem. 269 (37), 23286-23289.

Weaver, J.D., Huang, M.H., et al., 2002. Interleukin-6 and risk of cognitive decline: MacArthur studies of successful aging. Neurology 59 (3), 371-378.

Williams, L.M., Lali, F., et al., 2008. Rac mediates TNF-induced cytokine production via modulation of NF-kappaB. Mol. Immunol. 45 (9), 2446-2454

Wilson, C.J., Finch, C.E., et al., 2002. Cytokines and cognition-the case for a head-totoe inflammatory paradigm. J. Am. Geriatr. Soc. 50 (12), 2041-2056.

Wright, C.B., Sacco, R.L., et al., 2006. Interleukin-6 is associated with cognitive function: the Northern Manhattan Study. J. Stroke Cerebrovasc. Dis. 15 (1), 3438

Yirmiya, R., Winocur, G., et al., 2002. Brain interleukin-1 is involved in spatial memory and passive avoidance conditioning. Neurobiol. Learn. Mem. 78 (2) 379-389.

Young, E.E., Baumbauer, K.M., et al., 2007. Lipopolysaccharide induces a spinal learning deficit that is blocked by IL-1 receptor antagonism. Brain Behav. Immun. 21 (6), 748-757.

Ziemann, U., Ilic, T.V., et al., 2004. Learning modifies subsequent induction of longterm potentiation-like and long-term depression-like plasticity in human motor cortex. J. Neurosci. 24 (7), 1666-1672. 